\title{
MÉXICO EN LA EXPOSICIÓN UNIVERSAL DE 1889*
}

\section{Clementina díaz y de Ovando}

La República francesa celebró el primer aniversario de la Revolución, de la toma de la Bastilla con una magna Exposición Universal en el Campo de Marte de la ciudad de París, que se inauguró el 5 de mayo de 1889 y se clausuró el 31 de octubre de ese año.

De este certamen y de la participación de México, Fausto Ramírez hace un muy completo relato en su ponencia: "Dioses, Héroes y Reyes Mexicanos en París, 1889". En este apretado ensayo analiza muy acuciosa y penetrantemente la "solución arquitectónica y, en particular el programa iconográfico que orientó la decoración del pabellón destinado a contener los productos mexicanos mostrados en París, y el significado que este edificio tuvo en el contexto de dicho certamen". 1

Fausto Ramírez cumple con creces su propósito ya que estudia a fondo la arquitectura, el diseño, el estilo y los elementos que conforman el edificio neoazteca que México levantó en el Campo de Marte, también señala las fuentes, interpreta el misterio y complicado simbolismo de la decoración. Así como la importancia y trascendencia que el pabellón mexicano alcanzó en la Exposición Universal de 1889, ya que "sincronizaba perfectamente con las expectativas políticas, económicas y artísticas del momento".

Muchas fueron las fuentes mexicanas y extranjeras consultadas por Fausto Ramírez:

...la principal la constituyó un libro poco conocido, redactado a la sazón pớ el periodista mexicano José Francisco Godoy: México en París. Reseña de la partici-

* Agradezco al maestro Fausto Ramírez el haberme proporcionado las fotografías que ilustran este artículo.

${ }^{1}$ Ramírez, Fausto, "Dioses, Héroes y Reyes Mexicanos en París, 1889", en Historia, Leyendas y Mitos de México: su expresión en el Arte, XI Coloquio Internacional de Historia del Arte, México, UNAM, Instituto de Investigaciones Esteticas, 1988, p. 205. 
pación de la República Mexicana en la Exposición Universal de París en 1889, que ostenta un doble pie de imprenta: la Tipografía de Alfonso E López (1888) y la Tipografia de José F. Godoy (1890). Fue, pues un texto de "ocasión" escrito sobre la marcha, donde el autor reprodujo una gran cantidad de documentos oficiales, (minutas y notificaciones ministeriales, cartas, memorias, listas de participantes, nóminas de premios, etcétera) y notas periodísticas que van configurando la crónica del evento reseñado, generosamente ilustrado con litografias ejecutadas en el Taller de $\mathrm{H}$. Inarte. ${ }^{2}$

Confiado -dice Ramírez- en la copiosa recopilación de Godoy, no llevó a cabo la necesaria rebusca de archivos y hemerografía, en esta última hubiera encontrado muchas noticias.

De esta Exposición la prensa periódica que se publicaba en la Ciudad de México proporcionó una abundosa información, asaz interesante pues transcribe las opiniones de la prensa extranjera relacionadas con la imagen que nuestro país proyectó en esa Exposición: país riquísimo con recursos naturales y también la impresión que produjo la arquitectura del pabellón mexicano de inspiración prehispánica, así como su ornamentación, asimismo reprodujo los juicios muy importantes y elogiosos acerca de la producción artística que engalanó el pabellón: la pintura de José María Velasco y sus discípulos. En esta prensa no se deja de lado la divulgación de la crítica sobre la pintura austro-húngara, la italiana e inglesa exhibida en el Palacio de Bellas Artes la que sin duda debió ver José María Velasco; crítica que ponía a la vez de manifiesto las tendencias artísticas que prevalecían en Europa.

El Diario Oficial del Supremo Gobierno de los Estados Unidos Mexicanos, desde que México el 27 de diciembre de 1887 aceptó la invitación del gobierno francés para asistir al gran certamen, empezó a publicar todo lo referente a este suceso. En 1888 entre muchísimas informaciones, documentos, difundió los proyectos para la creación del pabellón mexicano; las comisiones, los nombramientos, los reglamentos, las circulares a los gobernadores, su respuesta y entusiasmo, las juntas, los concursos artístico-literarios, los de música, los dictámenes. En 1889 dio a conocer los cablegramas enviados desde París a los ministros de Fomento y de Rela-

\footnotetext{
${ }^{2}$ El pie de imprenta: Tipografía de Alfonso E. López (1888) se debe a que Godoy inició en ese año su reseña, lo que se comprueba con esta nota aparecida en el Partido Liberal de 6 de julio de 1888 .

México en París. Acusamos recibo de la segunda entrega de esta interesante publicación,

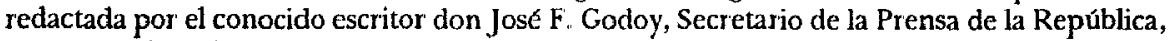
y que contiene la reseña de la participación de la República Mexicana en la Exposición Universal de París de 1889.
} 
ciones Exteriores, tanto por el Ministro plenipotenciario de México en Francia, Ramón Fernández, como por el Comisario general de la Exposición Mexicana, Manuel Díaz Mimiaga, cablegramas en los que daban cuenta ya de la inauguración del pabellón, ya de las opiniones de los visitantes, ya del éxito de Méxiço en el Certamen.

De los periódicos consultados - no era posible revisarlos todos-aparte del Diario Oficial, El Siglo Diez y Nueve, El Monitor Republicano, La Voz de México, El Municipio Libre, El Nacional, El Partido Liberal, Le Trait d' Union, El Partido Liberal, fueron El Siglo Diez y Nueve, decano de la prensa mexicana, y El Monitor Republicano los que más insertaron en sus columnas las noticias, comunicaciones y artículos sobre la Exposición Universal y el pabellón mexicano que se publicaron en París por periodistas franceses y los corresponsales de otros países.

Por considerarlos de interés consigno aquí algunas de esas noticias y varios artículos espigados en los mencionados periódicos.

El $1^{\circ}$ de marzo, El Monitor: en México en la Exposición de París, notificaba que el gobierno del Distrito Federal, había dirigido desde hacía algún tiempo una circular a varias personas, en donde se les hacía de su conocimiento que el Presidente de la República, antes de aceptar la invitación deseaba saber con qué elementos podía contarse para que México concurriera a la Exposición de una manera digna.

El Diario Oficial el 6 de marzo dio a la publicidad un amplísimo documento sobre los acuerdos tomados sobre la Exposición Universal. Cito únicamente lo que se refiere a la participación de México en la Exposición de París y al arte.

Aceptada la invitación el Presidente de la República aceptó que la organización de los trabajos relativos, así como su dirección quedasen encomendadas a la Secretaría de Fomento a la que por ley le compete.

Sección Oficial Reglamento para la Exposición Universal de París en 1889 y documentos anexos. Bases generales. Dirección general, Delegado del gobierno en París sus obligaciones. Comisiones especiales...

En el Capítulo VIII. Disposiciones generales se fijaban los requisitos a que debería de sujetarse la obra de arte.

Art. 35. Ninguna obra de arte ni producto alguno podrá retirarse antes de la clausura de la Exposición, a menos de autorización especial para ello.

Art. 36. No se admitirán para remitir a la Exposición sino las obras de arte ejecutadas con posterioridad al $1^{\circ}$ de mayo de 1878 . Las obras de arte a 
que se refiere esta prevención, son las incluidas en los siete géneros siguientes:

$1^{\circ}$ Pintura; $2^{\circ}$ Dibujo; Acuarela, pastel, miniatura, esmaltes, porcelanas, patrones para vitrales, excluyendo los que sólo representan asuntos de ornato; $3^{\circ}$ Escultura; $4^{\circ}$ Grabado; $7^{\circ}$ Litografia.

Quedarán excluidas: $1^{\circ}$ las copias, aun aquellas que reproduzcan una obra de un género diferente del original; $2^{\circ}$ los cuadros o dibujos que no tengan marco; $3^{\circ}$ las esculturas de barro sin cocer.

... Libertad y Constitución. México, Fcbrero 15 de 1888. - Pacheco

Después de estos reglamentos y anexos el Diario Oficial incluía el reglamento general francés. Copio sólo lo referente a las obras de arte.

República francesa. Ministerio de Comercio e Industria Exposición Universal de 1889 en París.

Reglamento General Acuerdo ministerial, expedido el 26 de agosto de 1886. Anexo número 1

Sistema de clasificación general.

Primer Grupo

Obras de Arte

Clase $1^{\mathrm{a}}$

Pinturas al óleo.

Pinturas sobre tela, sobre tabla, tableros y sobre diversas preparaciones.

Clase $2^{\mathrm{a}}$

Pinturas diversas y dibujos.

Miniaturas, acuarclas, pasteles y dibujos de todos géneros; Miniaturas sobre esmalte, loza, porcelana; patrones para vitrales y frescos.

Clase $3^{\text {a }}$

Esculturas y grabados en medallas.

Esculturas de bulto; bajo-relieve; esculturas de realce y cinceladas, medallas, camafeos, piedras grabadas. Grabados en hueco.

Clase $4^{\mathrm{a}}$

Dibujos y modelos de arquitechura.

Estudios y fragmentos. Planos y proyectos de edificios. Restauraciones según ruinas y documentos.

Clase $5^{\mathrm{a}}$

Grabados y Litografias.

Grabado en negro; grabados polícromos. Litografias en negro, a lápiz o a pincel; cromolitografía.

El 10 de marzo el Diario Oficial dio a conocer el nombramiento de Manuel Díaz Mimiaga, de fecha 27 de febrero de 1888, como "Delegado 
del Gobierno para entenderse con el Ministro de Comercio e Industria de la República francesa, en lo relativo a la Exposición Internacional que se ha de verificar en aquella ciudad el año de $1889^{\prime \prime}$.

Y también publicó la circular dirigida a los gobernadores de los Estados por el Ministro de Fomento, general Carlos Pacheco pidiéndoles su cooperación para que México se presentara honrosamente al Certamen, en donde daría a conocer la riqueza y variedad de sus recursos naturales, su naciente industria y sus producciones científicas, artísticas y literarias.

La próxima Exposición Universal ofrecía a México la brillantísima oportunidad de mostrar su progreso, su cultura y recibir a cambio, bienes materiales y morales:

... uno de esos bienes podria ser y será inmenso, el de acrecentar la respetabilidad de la nación, probando que a través de dificultades de que ha sido irresponsable, y a pesar de ellas ha conservado en sí vitalidad bastante para alcanzar en días no lejanos la grandeza y el poderío a que han podido llegar antes que ella otras más afortunadas. Podría además aprovecharse esta oportunidad para establecer una Exposición permanente en esta capital, a fin de favorecer asi el desarrollo del comercio, fuente inagotable de prosperidad y bienestar. A este objeto se han adoptado las medidas convenientes para que el edificio que ha de servir a la exhibición mexicana en el referido Certamen Universal, sea transportado a nuestro país una vez terminado aquel concurso. ${ }^{3}$

El 12 de mayo Antonio Peñafiel entregó su "Proyecto de edificio para el departamento mexicano en la Exposición de Paríis", y el 26 de mayo Antonio Anza hizo entrega del detallado informe de la parte técnica de la construcción. El Diario Ofizial publicó el 7 de junio los informes de Peñafiel y Anza; El Nacional los publicó el 9 de junio pues Peñaficl había favorecido al periódico con una copia.

Antonio Peñafiel "Jefe de la Comisión nombrada para formar un proyecto del edificio que constituirá el departamento de México en la Exposición Internacional que en el próximo año de 1889 se celebrará en París", daba cuenta al ministro de Fomento del resultado de sus trabajos; proyecto que siguiendo las instrucciones recibidas del ministro Pacheco: "representar el tipo caracteristico de algún o de algunos de los monumentos antiguos del país y a cuyo tipo se desea dar un carácter nacional en el

\footnotetext{
${ }^{3}$ El pabellón mexicano nunca fue reconstruiclo en México, para albergar esa Exposición permanente. De las vicisitudes del edificio y sus relieves nos da noticia Fausto Ramirez en su citada ponencia: "Dioses, Héroes, Reyes Mexicanos en París, 1889", pp. 252 y 253. Peñafiel creía que el edificio desmontado y trasladado a México sería adecuado para instalar en él un museo arqueologico
} 
extranjero", se amoldaba a esas indicaciones y "representaba una construcción de carácter exclusivamente mexicano".

El proyecto constaba -decía Peñafiel-de "dos partes esenciales: la construcción adecuada al objeto que se destina, y la forma que pudiera contener los rasgos principales que caracterizan nuestros monumentos y nuestra historia nacional". Como eran necesarios modelos para la construcción y materiales para la decoración, éstos fueron tomados en su mayor parte de "mi obra inédita titulada Monumentos del arte antiguo mexicano".

Peñafiel puntualiza el edificio: salón central, pabellones, galerías, escaleras, puertas, elevadores, iluminación, materiales y especifica la representación simbólica y ornamental.

La forma del edificio - señalaba Peñafiel- se había tomado de los antiguos teocallis aztecas y el ornato era de puro origen mexicano.

Datos muy interesantes suministrados, en lo que toca a la forma del edificio, del estudio que acabo de hacer al visitar el monumento de Xochicalco, del Estado de Morelos, monumento que por mi cuenta considero, en vista de sus signos hemerográficos, como la mejor página perteneciente a la antigua civilización regional del pueblo Tlahuica.

Como los templos han sido en lejanas épocas el verdadero resumen del arte antiguo, de ellos debía tomarse el modelo, no sólo para representar la antigua religión, sino también la antigua historia nacional, dos asuntos que han formado en todos tiempos la imagen fotográfica de los pueblos.

Podemos asegurar que en el proyecto que tenemos la honra de presentar a usted no hay adorno, ni símbolo, ni figura alegórica que no haya sido sacada auténticamente de la arqueología mexicana y con la única mira de revivir la genuina civilización mexicana.

Aclara Peñafiel que no se habían tomado los mejores materiales de Uxmal y Palenque "por no traspasar los límites de la arqueología mexicana". Fausto Ramírez advierte que no era posible "pedir una más paladina declaración del centralismo cultural y artístico".

No deja Peñafiel de recalcar la rica ornamentación del edificio: pintura, historia y atributos de los dioses, la historia antigua mexicana con sus reyes;

... la parte central del edificio representa las ideas capitales de la religión, los pabellones extremos, la agricultura y las artes, elementos principales de su progreso; y las figuras intermedias, el principio y el fin de la antigua civilización mexicana.

Si la comisión ha cumplido con su cometido, si ha conseguido restaurar en el proyecto que presenta las reliquias más importantes del arte antiguo mexicano habrá cumplido con dcber de verdadero patriotismo. (Documento número 1.) 
El Municipio Libre publicó los informes de Antonio Peñafiel y Antonio M. Anza los días 8, 9 y 11 de junio.

El 18 de junio El Municipio Libre consignó el "Proyecto del edificio para la Exposición Mexicana en la Internacional de París", de Luis Salazar, Vicente Reyes y José M. Alva.

Los autores daban santo y seña de los motivos prehispánicos tomados de Xochicalco, Palacio de Mitla, Palacio de Zayil, Monolito de Tenango, puerta subterránea del Palacio de Palenque, las Monjas, Kabak y, también de los libros inspiradores de su proyecto de los que asimismo habían tomado varios motivos: Lord Kingsborough, Waldeck, Alfredo Chavero, Dupaix y Charnay.

La comisión decía haber procedido con todo empeño y deseaba:

... que el proyecto del edificio que presento como resultado de sus estudios, sirva por lo menos, para cooperar al pensamiento de crear un estilo arquitectónico nacional. (Documento número 2.)

El proyecto elegido fue el de Peñafiel-Anza.

Fausto Ramírez expone las razones por las que se prefirió el proyecto Peñafiel-Anza.

Salazar, Reyes y Alva, a diferencia de Peñafiel y Anza no pararon mientes en utilizar un buen número de motivos mayas en su proyecto del edificio mexicano de 1889. Esto, sumado a la heterogeneidad visual (por no decir caos) que producía el conjunto de las tres fachadas diferentes planeadas para sendas caras del pabellón, fue tal vez, la razón para otorgar la preferencia al proyecto Anza-Peñafiel, mucho más unitario en lo visual y más acorde con la política cultural centralizadora del régimen de Díaz ${ }^{4}$

El gobierno de Porfirio Díaz puso énfasis en que México tenía que estar representado dignamente en la Exposición Universal para mostrar ante el mundo entero su adelanto material y cultural, otorgar de esta manera una auténtica y veraz imagen y disipar así, de una vez y para siempre, la malhadada neblina de desprestigio y calumnias que nos envolvía.

Peñafiel recoge en su proyecto la voluntad del gobierno de Díaz de identificar a México frente al mundo civilizado, identificación que sustenta en la orgullosa representación de la historia y el arte prehispánico. Esto es muy claro, en vísperas de la celebración del Cuarto Centenario del Descubrimiento de América o, como ahora se dice, el "Encuentro de Ambos Mundos" se quería resaltar y glorificar la civilización prehispánica, demostrar que México al momento de ese encuentro tenía una vigorosa tradi-

${ }^{4}$ Ramírez, Op. cit ., p. 220. 
ción histórica que Europa le negaba y, además, un gran arte original y monumental.

La revaloración de la historia y el arte prehispánicos había empezado desde antes del triunfo de la República (1867); con la restauración republicana adquiere ese movimiento un gran aprecio y carácter oficial.

En 1880 el arqueólogo francés Désiré Charnay hizo en México excavaciones arqueológicas y pretendió llevarse a Francia sus hallazgos. En un agitado y vehemente debate en la Cámara de Diputados (28 de octubre de 1880) los diputados le negaron el permiso; criticaron con acrimonia al gobierno por descuidar el patrimonio arqueológico, por no propiciar la investigación y las excavaciones; en la Cámara se sacudió la conciencia nacional y se despertó un gran interés por la arqueología y la defensa de ese patrimonio. Creo que el recuerdo de este debate no tan lejano a 1880-89, y que considero histórico, no dejó de tener su influencia en la decisión del gobierno para que el pabellón mexicano en la Exposición Universal de París fuera un enaltecimiento de la historia y el arte del México antiguo.

En 1881, en los concursos bienales de pintura, abundaban ya los temas prehispánicos. La gran inquietud por la arqueologia se patentiza en los Anales del Museo Nacional en 1887.

En 1884 se publica Historia Antigua y de la Conquista de Alfredo Chavero, primer tomo de México a través de los siglos, tomo aprovechado por Salazar, Reyes y Alva en su proyecto; con esta publicación el terreno quedaba dispuesto para el uso práctico del repertorio arqueológico, bastante estudiado por lo mismo venero de formas para los artistas. El arte mismo se encauzaba a la representación de nuestra historia, y muy en particular de lo prehispánico.

En el proyecto de Peñafiel no sólo es muy evidente el grado de madurez alcanzado por la revalorización de nuestro pasado cultural y artístico prehispánicos, sino también que en la Exposición Universal de París, se reconociera en toda su valía ese pasado al ser expuesto en una obra de interpretación nueva y revitalizada ante los ojos del mundo y, desde luego, como un punto de apoyo a ese nuestro nacionalismo tan anhelado, y que se sustentaba en una de las raíces más robustas y aceptada de la identidad de México.

Volviendo a las noticias periodísticas el 13 de junio El Partido Liberal se congratulaba del buen papel que los artistas mexicanos, como Jesús $F$. Contreras hacían en París. Contreras se encargaría de ejecutar los bajos relieves del pabellón mexicano.

El Partido Liberal el 22 de junio, avisaba que el día 18 habían partido a 
París los ingenieros Luis Salazar y Antonio M. Anza comisionados por la Secretaría de Fomento para que dieran inicio a la construcción del pabellón en la ciudad Lux.

Y el 5 de agosto El Partido Liberal incluía un cablegrama enviado con fecha 30 de julio por Díaz Mimiaga al ministro de Fomento en el que le comunicaba que habiendo sido sometidos al director de Ingenieros de la Exposición los dos proyectos para el edificio mexicano, ambos habían sido aprobados:

El director del Musco Etnográfico y otras personas caracterizadas, encuéntralos muy interesantes por su aspecto especial dando unánimemente preferencia al proyecto del $\mathrm{Sr}$. Anza, y asegurando que por la fuerza de su estilo proporcionará un éxito completo a México. Siendo muy limitado en tiempo, es imposible terminar el edificio si se emplea en formar dos presupuestos distintos.

En vista de esto proponemos a usted ocuparnos exclusivamente del proyecto Anza.

Suplico atendiendo a las razones expuestas se sirva decirme por cable si acepta nuestra iniciativa Díaz Mimiaga.

La propuesta del Delegado de México fue aceptada por el Presidente de la República y por el Ministerio de Fomento.

No es posible seguir paso a paso los detalles de la construcción del pabellón mexicano, así es que saltemos al mes de mayo de 1889 en que se inaugura las Exposición Universal.

El Nacional el 30 de mayo de 1889, en "Apertura de la Exposición. Detalles de la ceremonia", daba santo y seña de la iniciación del certamen.

A las dos de la tarde del día 6 del actual, el presidente Carnot, acompañado de muchos notables, llegó al lugar que está bajo la cúpula central del Palacio, para abrir la Exposición.

M. Carnot se colocó en el lugar de preferencia, rodeándole los ministros.

A las dos en punto comenzó la ceremonia. Todos los presentes se pusieron de pie.

El espectáculo era magnífico y nunca se había visto otro igual, desde el tiempo de Luis XIV.

La cúpula con pinturas que representan emblemas de las artes y la literatura, es soberbia, y en el sitio que cubre, adornado de gradería forrada de terciopelo rojo, tomaron asiento los senadores, los diputados, los magistrados, el clero, los miembros de la Academia francesa, los del Instituto de Francia, el Ayuntamiento, el Consejo general y los Funcionarios civiles y militares.

La reseña se detenía en todos los pormenores: los asistentes, las bellas damas vestidas muy chic, los veteranos apoyándose en oficiales jóvenes y 
robustos, representantes extranjeros, algunos como los orientales luciendo trajes lujosísimos, los africanos con plumas en la cabeza.

En su discurso el presidente Carnot, entre otras ideas, expresó que la Exposición de 1889 venía a ser un timbre de orgullo para Francia, que superando sus desgracias alcanzaba nuevos triunfos industriales y artísticos. A seguidas de pronunciar su discurso el presidente Carnot:

..... tocó varios botones, e instantáneamente brotó el agua en las fuentes y se puso en movimiento el gran motor de la máquinas.

Los trescientos o cuatrocientos mil espectadores estallaron en aplausos.

... En resumen, las fiestas dadas con motivo de la apertura de la Exposición, han sido una solemne demostración de que el mundo progresa en las artes y en la paz.

El 5 de junio El Nacional en "La Exposición Universal" decía que había treinta mil expositores, y pabellones de toda clase de materiales, de todas las formas imaginarias, con arcadas, cúpulas, miradores y torrecillas: "en fin reunir el afán de sobresalir, los gustos de todos los pueblos de la tierra, el estilo de cien arquitectos, y tendréis una vista del aspecto que presenta el terreno de la exposición".

El articulista llamaba la atención sobre los pabellones de México, el Salvador, Ecuador y Brasil, y apenas mencionaba el de Argentina y el de Chile que habían construido palacios de fierro que se llevarían una vez terminada la Exposición. Afirmaba que no se demoraba en los pabellones de Santo Domingo, Haití, Guatemala, Paraguay, Uruguay y Nicaragua por no tener carácter ni originalidad. El autor del artículo -carece de firma- avisaba que, en cambio, se detendría en el pabellón de El Salvador, la pequeña república centroamericana que había levantado un gigantesco palacio sugerido por su pasado indígena.

Las cuatro fachadas están decoradas con mármoles de brillantes colores y cada uno de ellos contiene una inscripción. Es una colección de símbolos de la antigua civilización americana. Los geroglíficos son obra del $\mathrm{Sr}_{\text {" Petor Comisa- }}$ riogeneral del Salvador, y estudiándolos con paciencia cualquiera puede llegar a ser americanista de primera fuerza.

In la fachada principal, hay figuras que representan los diez y ocho meses del año de los antiguos indígenas, y en el friso del primer piso está inscrita en el idioma de los indios esta fecha, 1889 . En la fachada posterior se ven los retratos de los reyes indigenas y los nombres de las ciudades de aquella República El signo que está junto a la efigie de los reyes indígenas indica según parece, que sólo ellos podían hablar en los consejos, lo cual ha de haber hecho muy sencillas las discusiones.

También México - comentaba el articulista- se había inspirado en su 
antigua civilización para construir su pabellón. La descripción nos descubre que no comprendió el mundo y el arte indígenà, no falta la crítica a los sacrificios humanos.

[El pabellón] cuyo aspecto severo recuerda los teocallis aztecas, llama la atención y hemos oído preguntar a más de una persona: ¿Qué es eso? ¿Un depósito de agua?

Figuráos una mole piramidal, cuyas fachadas tienen 70 metros de largo y 14 metros, 50 centímetros de alto, sin más apertura que una puerta, puerta sombría que parece la puerta del infierno. El interior recibirá luz por un techo de cristales. En estas fachadas el arquitecto mexicano, el Sr. Peñafiel, que concibió el plan del edificio y el $\mathrm{Sr}$. Anza, que lo ha ejecutado, han puesto dibujos geométricos, escrupulosamente copiados de monumentos antiguos En la principal hay doce figuras de gran tamaño que representan a los idolos del antiguo imperio, aquellos dioses por quienes se inmolaban miles de víctimas humanas, abriéndoles el pecho con cuchillo de obsidiana y a los emperadores aztecas.

Para aquel que deseara ver más reproducciones de la antigua arquitectura americana, podría detenerse en el pabellón de la República del Ecuador que había levantado un templo completamente cuadrado.

Los caballetes en forma de signos de interrogación que lo coronan, los pájaros quiméricos de los frisos, las caras humanas que rodean las puertas, se han hecho conforme a los modelos que los exploradores franceses han traido al Museo del Trocadero. Cuatro ranas colosales guardan la entrada; por lo menos parecen ranas, pero bien pueden ser tortugas

El Nacional el 8 de junio insertó "Noticias de la Exposición" en este apartado se comentó que, exceptuando la maquinaria, las obras de oro y plata, las del lapidario y la fabricación de cristales, "las demás artes decorativas americanas dejan mucho que desear... por lo que hace al sentimiento de la construcción los norteamericanos son superiores a los europeos; en las artes decorativas los americanos son inferiores a los europeos".

En las "Noticias de la Exposición" se habla también de que Japón y Brasil se distinguen por el lujo de sus instalaciones, por lo que se refería a la América Española, los periodistas de París indicaban que la palma se la llevaba por sus construcciones características el Ecuador, y se añade

... ya hemos publicado unos apuntes sobre las instalaciones de cada una de las naciones de la América latina, entre ellas la de México, dirigida por el señor ingeniero Peñaficl

"En el buen éxito de la Exposición", también de esa fecha 8 de junio y aparecida en $\mathrm{El}$ Nacional se daba noticia de algunas opiniones recogidas 
por la prensa francesa sobre el feliz resultado del certamen. Opiniones expresadas por los periódicos ingleses, alemanes, americanos e italianos.

El sábado 22 de junio a las nueve de la noche se inauguró con bombo y platillos el pabellón de México.

El 24 de junio el Diario Oficial en "Inauguración del Pabellón Mexicano en París", publicó varios despachos cablegráficos alusivos a la apertura del palacio mexicano, la que había constituido todo un triunfo y un honor para México. Los comentarios habían sido por demás halagüeños. El presidente francés, Sadi Carnot había expresado al ministro plenipotenciario en Francia, Ramón Fernández que estaba muy complacido de ver la manera espléndida con la que México había participado en el Concurso Universal, instalando una exhibición que bajo muchos puntos de vista superaba y en mucho a las exposiciones que habían dispuesto las demás naciones amigas de Francia.

La Exposición de México, según Ramón Fernández, era por bastantes motivos una de las primeras, sin lugar a duda, entre los países que contribuirán oficialmente al brillantc éxito del Certamen Universal de 1889.

El Siglo Diez y Nueve el 25 de junio insertó algunos de los cablegramas en los que se informaba de la lucida inauguración del Pabellón Mexicano, a la que asistieron el presidente de la República francesa Sadi Carnot y su esposa, miembros del gabinete, cuerpo diplomático y consular, principales funcionarios públicos; sociedad mexicana e hispanoamericana; personas notables de la sociedad francesa y extranjera; todos los comisarios delegados a la Exposición; personal de la dirección de la explotación y trabajos públicos; representantes de toda la prensa francesa y extranjera; personas notables del comercio. Tocaron dos orquestas, una banda militar y se sirvió un esplendidísimo buffet. Entre señoras y caballeros hubo dos mil personas.

La inauguración del pabellón mexicano es la "única que se ha hecho de noche por una concesión especial del señor Carnot".

El 10 de julio El Monitor Republicano publicó "Extranjero. Carta de París, especialmente escrita para el Monitor Republicano. Promesas vanas. - La Torre Eiffel y la política. Las elecciones se adelantan. El pabellón mexicano.- Inauguración eminente. En esta carta, su autor Ernesto García Ladevesse, corresponsal de $E l$ Liberal de Madrid, informaba que la apertura del pabellón de México era esperada con impaciencia indescriptible, se decía que asistiría el presidente de Francia.

García Ladevesse hacía una prolija descripción del palacio de México, la construcción más interesante desde el punto de vista arqueológico y, sobre todo, la más severa y monumental. "En ella la línea recta domina: las 
grecas que la adornan son de muy buen gusto. Representa un palacio azteca donde se ven brillantes vestigios de aquella civilización que ya florecía en la época del descubrimiento."

En la "construcción extraña" del pabellón comenta García Ladevesse, es en la fachada donde se encuentra todo el interés. "El modelo de las cariátides había sido encontrado por el doctor Antonio Peñafiel en las excavaciones de Tula; antiguo centro de civilización de los toltecas, y representaba un hombre cubierto con un casco hecho de la cabeza de una serpiente, el hombre lleva sobre el pecho un escudo, signo distintivo de los personajes de la época."

En cuanto a la decoración del grandioso pabellón mexicano, ostentaba una perfecta armonía entre la interior y la riqueza arqueológica del exterior.

El Monitor también ese día 10 de julio incluyó en "Noticias varias" la correspondencia dirigida desde París al Liberal de Madrid por García Ladevesse en la que este corresponsal daba su parecer acerca de la pintura española exhibida en el Palacio de Bellas Artes de París.

El 13 de julio, El Siglo incluyó "Cartas de París. [Por cable a la Presse Publishing Company, de N. Yok.] Traducido para el Siglo XIX París, $1^{\circ}$ de julio de 1889". En estas "Cartas" se daba razón de la venta de la famosa "Colección Secreta en la Galería de Pintores Seldelmeyer". No está por demás conocer las pinturas que se vendieron, así como los precios que por ellas se pagaron, por lo que "Cartas de París" figura como documento número 3.

Mientras la prensa liberal, se congratulaba del éxito de la Exposición Universal de París y de la participación de nuestro país $L a$ Voz de México, periódico ultramontano, el 14 de julio en su editorial, "Una fiesta de la impiedad", se lanzaba iracunda contra la Revolución francesa de 1879, y condenaba a la Exposición Universal por tener como principal objetivo

... solemnizar con una impía fiesta el suceso más desastroso de nuestros tiempos. Ella pretende glorificar y mostrar victoriosa la rebelión llevada en este siglo hasta el último extremo, del hombre contra Dios, de la iniquidad contra la justicia, de la impiedad contra la Religión verdadera.

... Los palacios tiendas o pabellones, de los productos industriales y sobre todo, diversiones de todo género, ofrecen allí un colosal saráo y constituyen a la populosa ciudad en una Babilonia del siglo XIX.

El Siglo el 17 de julio en "El Pabellón Mexicano en la Exposición de París" proporcionaba a sus lectores la reseña sobre la inauguración del Pa- 
bellón mexicano, "hermosa y grande construcción de estilo exótico, estaba alumbrada por dos grandes trípodes en los que ardían fuegos rojos del más bonito efecto. La Exposición propiamente dicha resplandecía de luces." (Documento número 4.)

El 20 de julio El Siglo en "Inauguración del Palacio Mexicano. En el campo de Marte", traducía de un periódico francés - no dice de cuál- la inauguración oficial del "soberbio palacio que el gobierno de México ha hecho levantar en el campo de Marte, para que en él fueran expuestos los productos tan variados como ricos de la industria y del suelo mexicano".

Explicitaba el periódico francés que antes de comentar la fiesta brillantísima con la que se había inaugurado a las nueve de la noche y con la asistencia del Presidente de la República francesa y su esposa, el pabellón de México, se veía obligado a demorarse en los detalles acerca del imponente edificio que admiraban los visitantes de la Exposición, "pues no había en todo el Campo de Marte, ninguna construcción que sea más curiosa bajo el punto de vista arqueológico, que la que se debe a la ciencia y al talento de los señores Peñafiel y Anza".

El diario describè sin omitir detalle el "palacio azteca", pondera su ornamentación, la exuberante manifestación histórica, religiosa y arqueológica, el simbolismo, la grandiosidad y sobre todo, la innegable belleza de las grecas de los frisos, la variedad de las cariátides, en suma, su arte.

La fiesta de inauguración - según el diario- no dejó nada que desear, todo salió a pedir de boca. La iluminación de la fachada ponía de relieve "las líneas majestuosas y los detalles originalidades de la rara construcción", ese torrente de luz eléctrica inundaba la fachada y maravillaba a la gran muchedumbre arremolinada en las cercanías del edificio, la que pregonaba a voces su asombro "por la idea reconstructora de una original arquitectura y desconocidla ya".

El interior del palacio presentaba un golpe de vista realmente feérico; globos incandescentes distribuidos con profusión, aumentaban el brillo deslumbrador de los ricos minerales, la transparencia de los ónix, la coloración de los tejidos atigrados y los matices de las maderas preciosas de esta exposición, una de las más bellas y, sin duda, la más completa de todas las que figuran en el Campo de Marte.

El buffet abundante y exquisito fue servido de una manera regia. Una selecta y elegantísima concurrencia, tanto de la colonia mexicana como de la hispanoamericana residente en París, dio gran realce a la fiesta. Bellas y graciosas jóvenes con su presencia hicieron que la inauguración tuviera aún más lucimiento. 
El Presidente de Francia y su esposa felicitaron con gran vehemencia a los organizadores de la exposición mexicana, en donde se hacía patente no únicamente

... la profusión de las riquezas del suelo de México, sino también los grandes progresos realizados por la industria nacional, y por el grado elevado que las ciencias como las letras han alcanzado en la República.

El cronista no regateaba las felicitaciones a los organizadores de tan admirable exposición: el Presidente de México, el ministro de Fomento, general Carlos Pacheco, este último apoyado por el jefe del Estado, había realizado prodigios para llevar a buen fin esa exposición, que ante el mundo entero revelaba las riquezas de todo género donadas por la naturaleza a la tierra mexicana, ticrra de increíble porvenir. (Documento número 5.)

El 23 de julio El Siglo en "Todavía un Pabellón Mexicano en la Exposición de París", reproducía una opinión más sobre este monumental edificio, por lo demás muy encomiástica.

En una correspondencia de París que publica un periódico de Nueva York, el Atisador Hispanoamericano, encontramos las siguientes líneas referentes al Pabellón mexicano recientemente inaugurado como ya saben nuestros lectores, en el certamen universal de París.

Véase el templo mexicano. La forma extraña de este edificio ha sido tomada de los antiguos Teocallis aztecas, y especialmente del monumento de Xochicalco, que es por sus signos cronográficos la más bella página de la antigua civilización mexicana. Este templo es inmenso, mide 70 metros de longitud por 14.50 de elevación, y se compone de una parte central y dos pabellones laterales. Una serie de grabados, carácter principal de los antiguos templos, conduce al pórtico, donde hay dos cariátides extrañas, que tiene por coronamiento el símbolo del sol, Tonatiuh, presidiendo la creación de Cipactli, que representa la fuerza fertilizante de la tierra, por la cual se alimenta el género humano.

En los nichos practicados sobre la fachada principal, doce grandes figuras en relieve representan a los dioses de la antigua mitología mexicana y a los emperadores del principio y fin del antiguo imperio.

El interior está perfectamente preparado para recibir los productos y darles la luz necesaria. Una decoración al fresco de las más originales y muestrarios de cristal de formas características hacen de esta instalación uno de los rasgos más característicos de la Exposición ${ }^{5}$

${ }^{5}$ Esta descripción del pabellón mexicano y otras más publicadas por la prensa extranjera reconocen como fuentes de información, el texto explicativo "que para hacer más comprensible el programa decorativo del edificio escribió Peñafiel que se publicó en edición trilingüe (castellano, francés e inglés). El autor se ocupaba en primer lugar de la descripción del edificio 
El Siglo el 26 de julio en "Todavía la inauguración del pabellón mexicano en la Exposición de París. De Las Novedades de Nueva York", transcribía de este diario el gran suceso que había sido la inauguración del palacio mexicano y la impresión causada entre los asistentes por su original arquitectura.

José Sánchez Somoano, autor de esta correspondencia, fechada en París en junio de 1889 , aclaraba que conocía algunos de los soberbios monumentos prehispánicos $\mathrm{y}$, por lo mismo, los enaltecía, ya que proclamaban la poderosa civilización de los antiguos mexicanos, comparable a la de Grecia. Algunos de los elementos más bellos de los monumentos prehispánicos se recreaban en el increíble pabellón de México. Sánchez Somoano sostenía que el arte prehispánico que se podía admirar en el pabellón de México, contribuiría, sin lugar a dudas, al enriquecimiento del arte universal. El tiempo daría la razón al corresponsal de Las Novedades.

Ha sido un verdadero acontecimiento en París la inauguración de este pabellón porque como ya hemos dicho en una anterior correspondencia viene a ser el único de estilo propio entre las repúblicas hispano-americanas, aunque el Ecuador y el Salvador también trataron de hacer algo, pero en pequeña escala.

El antiguo y poderoso imperio de los aztecas, por su cultura y por sus costumbres tiene muchos puntos de contacto con la antigua Grecia. Por lo tanto no es extraño que el "Teocalli" (Casa de Dios) "Teopantli" (Templo) o "Tecpan" (Palacio real) levantado en el Centro de Marte por el gobierno mexicano para exhibir sus productos, esté llamando vivamente la atención de este pueblo, hoy más que nunca cosmopolita

En el hermoso pabellón, el mejor de las Repúblicas hispano-americanas, se ajusta en todo a las exigencias del arte antiguo mexicano, y recuerda a los que conocemos algo de esa República, la preciosa pirámide de Papantla y ruinas de Tusapan, en el Estado de Veracruz; las de Xochicalco, en el de Morelos; las de Uxmal y Chichén Itzá, en Yucatán; las del soberbio Palenque, en el de Chiapas; $y$ otras muchas que dan ventajosísima idea del alto grado de civilización que en los tiempos antiguos alcanzaron todos los pueblos del vasto territorio mexicano.

Todo el decorado interior, las pinturas y hasta la estantería, están sujetas al mismo estilo, y nada desdice en los más pequeños detalles del plan que se siguió para representar un verdadero azteca.

Si por la reconstrucción de este estilo arquitectónico que viene a enriquecer el arte, y a no dudarlo a traer muchos prosélitos, merece México los mayores plácemes, no menos lo merece por la exhibición que hace de los productos de su suelo, de su trabajo, de su inteligencia.

y en segundo de su representación simbólica y monumental." (Fausto Ramírez, "Dioses, Héroes y Reyes Mexicanos en París 1889", p. 217. El título del libro de Peñafiel es: Exposición del edificio mexicano para la Exposición Internacional de Paris, en 1889. Libro que debió haber sido muy difundido y conocido por los cronistas de la Exposición. 
Sánchez Somoano menciona también con elogio la "Ilustración Pública", la "Agricultura" y ante la "Minería" se queda estupefacto,

... en esta sección México echó el resto, como vulgarmente se dice. No se puede concebir ya más.

Para acercarse a ella es preciso levantarse temprano y tomar sitio. Después, quédanse los pies como petrificados, la boca abierta y las pupilas dilatadas. iOh que atracción tan irresistible la de estos brillantes pedruscos!

Por último el corresponsal aseguraba que la nación mexicana estaba haciendo en el certamen un magnífico papel. Felicitaba a México por su pabellón, por la muestra de sus productos, y desde luego, por su ascendente progreso.

El 30 de julio el Diario Oficial en el "Pabellón Mexicano en la Exposición de París", Díaz Mimiaga informaba a la Secretaría de Estado y Despacho de Fomento con fecha 4 de junio del éxito de la apertura del Pabellón y entre otras cosas decía,

.... he tenido la satisfacción de escuchar de las personas indicadas y del público en general frases como la siguiente: Si el exterior de vuestro palacio es clásico y majestuoso, el interior es sobcrbio y extraordinariamente interesante

El Siglo el 2 de agosto, en "La Exposición Mexicana. El maguey, el pulque, el mezcal", tomaba del periódico parisiense Le Temps de fecha 12 de julio el artículo firmado por Paul Bourde sobre la instalación mexicana en el Campo de Marte. En el sentir de Bourde la Exposición de 1889 era una ocasión única para que Europa pudiera conocer a los países hispanoamericanos, unidos éstos a Francia por los recios lazos de espíritu y la cultura. Para los dos pueblos México y Francia venía a ser la ocasión de una mejor relación primordialmente económica, que propiciaría un activo comercio $y$, también un mayor acercamiento espiritual.

Bourde reconocía, ante todas cosas, la sorprendente conducta de los mexicanos con respecto a los franceses, los que habían asolado a México con una guerra cruel e injusta $y_{s}$ sin embargo, no por eso guardaron rencor a Francia. El pueblo mexicano sutilmente supo distinguir entre el agresor Napoleón III y el pucblo francés. Ambas naciones terminada la lucha pronto sinticron renacer su mutua attacción como lo demostraba la actitud del ministro de México en Francia, Ramón Fernández.

Después de estas reflexiones acerca de la simpatía que ataba a franceses y mexicanos, Bourde indicaba que la Exposición Mexicana por sus productos y por su arte, era un museo. 
¿Es aquella una Exposición? Mejor sería llamarle un Museo, México ha querido mostrarse ante el mundo tal cual es, y para conseguirlo, se han acopiado muestras de todos los productos imaginables, tanto de aquellos que únicamente pueden utilizarse en el consumo local, como los que interesan al comercio exterior.

Aún existe una exposición de pintura en la cual la serie de paisajes exactos y bellos, debidos al pincel de Velasco, os dan a conocer varios de los lugares más célebres del país; ahí podéis contemplar a México y sus lagos, el árbol de la Noche Triste, bajo el cual lloró Cortés lágrimas de desesperación, la aldehuela en donde nació Juárez, la ciudad donde vio la luz primera Porfirio Díaz, etc.

Finalmente ahí aprenderéis todo lo que se puede saber de México sin ir a él.

Aunque en concepto de Bourde el pabellón de México se significaba por su gran alarde de originalidad colmada, "en el que los señores Peñafiel y Anza han hecho que reconozca el sombrío genio de los aztecas", aconsejaba que mejor que visitarlo se dieran un paseo por los alrededores del pabelón en donde se encontraban veinte áloes. Bourde suministraba muchos datos sobre el maguey, su cultivo, su utilización. Del pulque contaba cómo se obtenía esa bebida, relataba su leyenda, la que podía atestiguarse con una pintura.

Debemos a los antiguos aztecas el uso del cacao; ellos fueron también los inventores del pulque y asignaban fecha precisa a este descubrimiento.

En la Exposición de pintura, instalada en el primer piso del Palacio, un cuadro de José Obregón recuerda la leyenda referente a dicha invención.

Reinando Tecpancatzin, cierta joven quedó encargada de ofrecer al rey una copa de la nueva bebida Meconetzin, que quiere decir, hijo de maguey. (Maguey es el nombre indígena del ágave mexicana.) Meconetzin reinó después.

El Nacional el 6 de agosto en "Fuera del país. El pabellón mexicano en la Exposición de París", difundió un interesantísimo artículo traducido del periódico el Faro del Loire y signado por León Cahun.

El articulista empezaba diciendo que si fuera dable en Europa o en América ver cómo un pueblo dominado y absorbido por otro, rescataba su autonomía, su personalidad y reivindicaba con altivez su origen, se le observaría con interés y se le aplaudiría por sus triunfos.

Gahun sostenía que las civilizaciones vivían de lo que tomaban de otras y que un pueblo que negara deberle algo a los demás acabaría por agotarse, tanto por el exceso de sus propias virtudes, como por sus defecios; la pureza, por lo tanto, perjudicaba a las razas, las tornaba viejas y estériles y para que produjeran era forzoso la fecundación de la guerra y el comercio. Pero también se precisaba que en ese contacto brutal no perdieran su individualidad ni su autonomía primitiva. Las agrupaciones de hombres 
que impropiamente se llamaban razas, sólo podían eclipsarse en su primera infancia o cuando llegaban a la adolescencia, a la conciencia de su valía, pero no desaparecerían si no se empeñaban en su destrucción.

Los etnógrafos triviales y pedantes aseveraban necedades, vulgaridades tales como que los autóctonos americanos, los indios, tenían que desaparecer para dejar paso a los inmigrantes europeos que los reemplazarían.

Basta - afirma Cahun - ver la Exposición Mexicana para darse cuenta de la sinrazón, de las equivocaciones de los simplones etnógrafos, pues donde quiera que hay vigorosas poblaciones indígenas, sucede lo contrario: los inmigrantes europeos desaparecen absorbidos por la raza autóctona

bajo la influencia de la conquista española, los que habitaban en México se han modificado, pero no han perdido su carácter particular, y si los mexicanos de hoy no son exactamente iguales a los de la época anterior a Hernán Cortés, no por eso dejan de ser verdaderos mexicanos, es decir, verdaderos autóctonos, orgullosos de su origen.

Más de un europeo se sonreirá al penetrar en la Exposición Mexicana, al ver el modelo de un monumento levantado a la memoria y a la gloria de héroes que tienen los nombres extraños de Cuauhtémoc y Cuitláhuac. Un americano se sonreirá al ver en Francia los monumentos de héroes como Ambiorix o Vercingetórix. Los mexicanos de este siglo son respecto de los compañeros de Cuitláhuac y Cuauhtémoc, lo que somos los franceses respecto a los compañeros de Vercingetórix y Ambiorix. Así como los celtas, los belgas, los ligurios, los iberos se convirtieron en galo-romanos; los aztecas, los toltecas, los chichimecas se han convertido en mexicanos

Cahun agregaba que así como los galo-romanos sostuvieron luchas terribles contra los germanos, los hispanos-aztecas tendrían que luchar contra sus formidables vecinos los yanquis y vaticinaba que no era improbable que, con el tiempo, se formara una raza mixta enérgica y trabajadora, como la que se había formado al Noroeste de Francia entre francos y galos.

De esta unión nacerá tal vez una República poderosa, cuyos hijos tendrán a orgullo descender de los indios y con el tiempo se verá que los descendientes de los compañeros de Cortés y de William Penn harán alarde de proceder de Nezahualcóyotl

Todo es posible en el mundano suelo - sentencia el refrán- ¿en los Estados Unidos, país de muchas razas, nacerá esa República que presagiaba Cahun?

Después de estas reflexiones Cahun ha llegado a lo que le interesa, demostrar que los mexicanos han superado los obstáculos, han asimilado influencias, han sabido preservar su identidad, sus tradiciones, su perfil 
histórico y artístico, en resumen, su cultura. El testimonio de Cahun es, en síntesis una loa a México. En este panegírico que le sugiere la visita al pabellón mexicano, disminuye acaso, sin querer, a otras naciones de América.

Sea como fuere, lo que más llama la atención en la Exposición de México, es su autonomía. De todas las naciones del Nuevo Mundo es la más americana, la de más color local. Esto proviene probablemente de que México es el pueblo americano que posee más antiguas tradiciones, y si la antigüedad y las tradiciones son títulos de nobleza, México representa la aristocracia de América. De todos sus vecinos grandes y pequeños, sólo México presenta pruebas artísticas, literarias e históricas que cuentan cuatro siglos de existencia; junto a los Estados Unidos, junto a los oscuros hispano-indígenas del Sur, es como un abuelo rodeado de Teocallis, de sus templos, de sus papyros cubiertos de jeroglíficos que ya descifra los de su alfarería antigua, de sus telas tejidas a mano: es una nación vieja en esa región de naciones jóvenes que ha cruzado el acero con enemigos terribles, que tiene una historia militar que empieza en la Noche Triste y termina en Querétaro y a la cual nosotros los franceses que la conocimos en México, debemos tenderle la mano amistosamente.

¿Dónde se encuentra la fortaleza de México para resguardar su cara identidad nacional? En el arte, nos responde Cahun, en esa asombrosa y original pintura paisajística de José María Velasco, que a nadie imita, y cuyo estilo aunque diferente al de Corot y Rousseau, puede compararse con el de estos grandes artistas franceses. Cahun entusiastamente exalta los valores del paisaje viviente de Velasco: su novedad, sus amplios horizontes, la luminosidad, la nitidez del aire, el mágico colorido, la corrección del dibujo, la vitalidad de la composición y, ante todas cosas, la exactitud, la objetividad, la belleza inconfundible de su tierra nativa.

Fuerte en su pasado, México ha....

...vivido por sí mismo y así quiere seguir viviendo y engrandeciéndose. Una prueba de ello es la galería de pinturas instalada en el primer piso de su pabellón. Las otras naciones de América han producido pintores buenos o malos, algunos excelentes, cuyas obras se han podido ver en nuestros salones de Bellas Artes, pero esos pintores son discípulos de nuestras escuelas europeas, copistas de nuestros grandes maestros. México por su parte, tiene una escuela original, nacional que se ha formado ante el espectáculo de su cielo, de su aire, de su naturaleza. En América la única pintura auténtica es la mexicana Exageraríamos si dijéramos que todas las obras expuestas tienen valor estético; sin embargo, justo es aplandir los esfuerzos que se han hecho para reproducir las grandes escenas de la historia nacional, como el cuadro en que se representa a un orador mexicano hablando ante el Senado de Tlaxcala contra la alianza con Cortés o escenas de la vida real. Mas lo que ha sido para mí una revelación son los sorprendentes paisajes del Sr. Velasco y de sus discípulos. Sí, hay en 
México una escuela de paisajistas y una escuela que a nadie le debe nada, que a nadie imita, que se ha formado sola al contemplar la maravillosa vegetación de los valles, las perspectivas diáfanas de las montañas, la luz suave y transparente en todas partes.

El estilo de Velasco difiere tanto del de Corot y Rousseau como un paisaje de México de un paisaje del Valle de Sena; pero no por eso es menos riguroso ni menos bien expresado. El sabor exótico de esas reproducciones de la naturaleza, las montañas que en todas se ven, como el Popocatépetl y el Pico de Orizaba que brillan en los cuadros como el Fuji Yama en los japoneses y el Vesubio en los napolitanos, la frescura y el verdor de los campos, la abundancia de las aguas, lo grandioso de los panoramas y la claridad del aire y del cielo dan a esos lienzos un sello de originalidad, un encanto indecible, que es dificil encontrar en otros. Los clásicos nada pueden decir contra la corrección del dibujo, ni los impresionables de la vivacidad y la verdad de la composición.

El señor Velasco sabe hacer hablar a los árboles y a las montañas, de México se entiende; no sé lo que haría en Francia y tal vez una encina del bosque de Fontainebleau, le embarazaría mucho. Nadie es mejor escritor más que en su propia lengua; nadie es verdadero pintor más que en su patria: el Señor Velasco es un verdadero pintor y sus obras son hijas robustas y lozanas de su suelo natal.

Y con un último cumplido a México, Cahun da fin a sus reflexiones.

Después de ver los cuadros del Sr. Velasco, fuí a respirar un poco de aire porque hacía mucho calor en la galería, arriba de la galería que es una reproducción del terrible Taleluco (sic) donde cuenta Bernal Díaz que vio correr la sangre de sus compañeros durante los combates dados por Cortés.

Desde allí se ve el pabellón de la República Argentina, cubierto de dorados y arabescos de modo que parece el palacio de un hombre de fortuna improvisada. El bueno del Sr. Peñafiel, que fue mi guia en el pabellón y es ilustrado, patriota probado y hábil estadista, aunque es algo arqueólogo y filólogo notó que me fijaba yo en ese lujo argentino y me dijo: "Sí, son ricos; pero es una República honrada y bien gobernada," Tuve tentaciones de contestarle: "No poseen vuestro antiguo honor esos advenedizos", pero no lo hice y me comulgué la respuesta.

Han pasado cien años, Argentina se ha empobrecido, México no es el país opulento, cuyas riquezas tanto se encomiaron en la Exposición Universal, pero su arte, ese "antiguo honor" ahora en este nuestro siglo es expuesto y encumbrado en los más famosos museos del mundo.

Este artículo fue escrito antes de que se inaugurara el pabellón mexicano, tal se deduce de estos renglones.

Los recuerdos históricos se colocarán cuando la exposición mexicana esté completamente instalada e inaugurada; entonces hablaré de la sección de arqueología y algo de estadística, de industria y agricultura. 
¿Conoció José María Velasco este artículo de Cahun? Tal vez sí. En las cartas dirigidas a su esposa, Velasco le hacía saber que su pintura había producido muy buena impresión y llamado bastante la atención la naturaleza de México. El 2 de junio escribe,

...los cuadros mios han producido mucho efecto, agradan y se han sorprendido de ver que en México se pueden pintar estas obras que las juzgan de bastante mérito.

Y el 27 de junio sin abandonar su modestia dice,

...se ha escrito un largo artículo que habla especialmente de mis cuadros, hace tales elogios, que ha sido censurado por algunos mexicanos. Otros mexicanos también lo han leído con mucho gusto, y me han felicitado. Voy a ver si puedo traducirtelo, no se lo enseñes a nadie.

Lástima que Velasco no diga el nombre del autor del artículo. ¿Será el de Cahun? La clave se halla en la fecha en que el artículo de Cahun apareció publicado en $E l$ faro del Loire. La pintura de Velasco causó tanta admiración que bién puede ser otro artículo laudatorio.

El Siglo el 7 de agosto en "México en la Exposición" vertía del Petit National un artículo en el que se comentaba que una de las curiosidades de la Exposición Universal era, sin duda, el palacio mexicano inaugurado por Mr. Carnot. Por esa participación nacional y patriótica merecían toda clase de parabienes el Presidente de México, Porfirio Díaz y el Secretario de Fomento, Carlos Pacheco.

Inteligentes y prácticos los mexicanos - al decir del Petit Nationalvencedores en la guerra de Intervención, habían perdonado y comprendido el beneficio que les traería para el desarrollo de un intenso comercio con Europa unas relaciones cordiales. En consecuencia, la República mexicana había decidido festejar de una manera grandiosa el centenario de 1889 , dando a su concurso una importancia extraordinaria que sobrepasa a lo esperado por la opinión pública: su palacio artístico, de reminiscencias arqueológicas, rigurosamente nacional, guardaba los tesoros naturales y culturales de la pródiga tienra mexicana.

No se ha economizado ni dinero ni trabajo. El arquitecto del palacio, Sr. Anza, con presencia de los documentos que le facilitó el Sr. Peñafiel, construyó un monumento de verdadera arqueología y arte.

${ }^{6}$ Citado por Luis Islas García en su libro Velasco pintor cristiano, México, Ediciones Proa, 1932 , p. 43 
Es un palacio azteca, reconstruido conforme a los últimos descubrimientos que se han hecho en México.

El lado más notable de esa reconstrucción es la fachada, por lo que merece una descripción especial. (Aquí el periódico francés se ocupa de ella, y la omitimos por ser conocida de nuestros lectores.)

Por lo que se vé la exposición mexicana es una obra verdaderamente interesante por ser exclusivamente nacional.

El periódico Petit National hacía constar el éxito de la bella exposición mexicana, así como la amabilidad y exquisita educación de los miembros del comité mexicano.

El Monitor Republicano el 7 de agosto insertó "Los pintores mexicanos en la Exposición de París. León Cahun crítico francés, ha publicado este juicio con relación a la sala de pinturas en el palacio mexicano de la Exposición de París."

Este juicio no es sino una traducción muy poco distinta - como puede apreciarse - de la consignada por El Nacional de fecha 6 de agosto. ${ }^{7}$ La diferencia más notoria que se advierte es ésta: en El Nacional se traduce impresionables y en la de El Monitor, impresionistas. El Monitor hacía bien en dar a conocer esta excelente opinión crítica para que sus lectores se percataran de la importancia de José María Velasco y el reconocimiento que se le rendía en Europa.

${ }^{7}$ La versión del Monitor es ésta: Decir que todos los cuadros expuestos en esta galería tienen un valor estético sería demasiado exagerar; de todos modos bueno es reconocer y señalar los esfuerzos hechos en vista de pintar las grandes escenas del arte nacional, como aquella en que se ve a un orador mexicano hablando, ante el senado de Tlaxcala, contra la alianza de Cortés, o las escenas realistas de la vida popular. Pero lo que ha sido una revelación para mí, son los sorprendentes paisajes del Sr. Velasco y sus discípulos. Sí, hay una escuela de paisajes en México, y una escuela que no debe nada a nadie, que no ha imitado a nadie, que se ha formado sola mirando la maravillosa vegetación en los valles, los lejanos claros en las montañas, la luz dulce y transparente de las arquitecturas.

El arte del Sr. Velasco difiere tanto del de Corot o de Rousseau, como un paisaje de México difiere de un paisaje del Valle del Sena; pero no es ni menos hermoso, ni menos sinceramente explicado. El gusto exótico de sus bellas escenas naturales, los puntos de mira, que se encuentran por doquier como el Popocatépetl nevado y el Pico de Orizaba, que desempeñan en esta pintura el mismo papel que el Fousi-Yama en los trazos japoneses y el Vesubio en los cuadros napolitanos; el encanto y la rareza de los sitios, la fresca entonación de los verdes, la abundancia de las aguas, la amplitud de las perspectivas y el movimiento del aire y del cielo, dan a esas telas notables una originalidad, un aspecto sobresaliente que no he visto en ninguna parte. Los clásicos nada tendrán que decir a lo correcto del dibujo, ni los impresionistas a la vivacidad, a la vitalidad de la composición.

El Sr. Velasco sabe hacer vivir y hablar a los árboles y a las montañas en país de México, por supuesto: no sé lo que haría en Francia, $y$ tal vez un encino del bosque de Fontainebleau, visto bajo un cielo gris de noviembre, lo embarazaría mucho. Nadie es verdaderamente escritor sino en su lengua; nadie es verdaderamente pintor sino en su país; el $\mathrm{Sr}$ Velasco es un verdadero pintor y su pintura es la hija robusta y sana del suclo natal. 
Por su parte, El Siglo consideró una obligación orgullosamente legítima, enterar a sus lectores de la trascendencia que la pintura de José María Velasco alcanzaba en Europa, y ese mismo día 7 de agosto, divulgó la penetrante crítica de León Cahun, copiada de El Monitor.

El 8 de agosto El Siglo con "La República de los Estados Unidos Mexicanos en la Exposición Universal", daba inicio a la colaboración de M. Montmayeur publicada por La Presse Industrielle, "uno de los periódicos parisinos -en el sentir de El Siglo- reconocido por la respetabilidad de sus redactores y por la severidad de las apreciaciones contenidas en sus columnas ha sabido conquistarse gran renombre y puesto distinguido", de aquí el valor de esa colaboración que traducía El Siglo y difundió durante varios días.

El periodista proclamaba su agrado ante esa Exposición auspiciada por Francia, fiesta glorificadora del trabajo, rey del mundo y de la paz, madre de las grandes concepciones. La Exposición y, sus maravillas acumuladas en el Campo Marte, dejaría en la historia una huella luminosa, un ejemplo a seguir dado que abría un camino hacia la emancipación, "la luz se había hecho y no volverían las tinieblas".

Una gran multitud acudía a la Exposición para visitar más que las instalaciones francesas o las extranjeras, el pabellón de México, el soberbio "palacio azteca".

La inauguración del pabellón mexicano había sido - declara Montmayeur- de un esplendor incomparable, apertura de la que por mucho tiempo se conservaría el recuerdo. Ningún pormenor se le escapa al cronista: la hospitalidad, la cortesía de los miembros del comité, su perfecto dominio del idioma francés.

Al día siguiente 9 de agosto $E l$ Siglo prosiguió con la reseña de Montmayeur en la que éste refrendaba la esplendidez y el buen gusto de la Exposición de México, y cuyas innumerables riquezas allí exhibidas necesitaban un volumen entero para precisar elogios y detalles.

Montmayeur hacía una puntualizada crónica de la inauguración a la que habían asistido el Presidente de Francia, su esposa y numerosos invitados, la flor y nata elegante y de buen gusto de todo París.

El Presidente y su comitiva recorrieron la Exposición y después de subir por la majestuosa escalera que conducía a las galerías superiores, se detuvieron ante los mil productos del suelo mexicano: fauna, flora, minerales, su industria. En esa parte del edificio el presidente Carnot y sus acompañantes

han podido admirar también la exposición de cuadros, cuyos animados paisajes, pintados por el $\mathrm{Sr}$. Velasco constituyen su mayor parte. 
... Tanto la planta baja como las galerías estaban brillantemente iluminadas: era una profusión un despilfarro de luz, que hacía resaltar admirablemente los tonos cálidos y la brillantez de los objetos expuestos y que permitía apreciar la elegancia de la arquitectura azteca y los finísimos detalles de su ornamentación

Montmayeur no deja de lado la mención del regio buffet, la galantería mexicana, las damas fueron obsequiadas con primorosas y enormes bouquets. Damas que dieron lustre a la ceremonia de apertura con el esplendor de su belleza y la elegancia de preciosas toilelles. Mme. Carnot con un vestido de seda azul broché y la encantadora mexicana señora de Díaz Mimiaga fueron el centro de todas las miradas

En su resumen, la inauguración había sido de lo más espectacular y la soirée espléndida; los mexicanos demostraron que, para recibir como grandes señores, se pintaban solos.

El cronista reconocía que México no había economizado sacrificio alguno para llevar a buen fin su magna Exposición y para presentarla dignamente en el suntuoso y encantador palacio que le albergaba. Exposición que era una prueba de amistad para Francia y que ésta sabía apreciar.

Montmayeur auguraba a México un grandioso futuro, una era de prosperidad que no tendría límite ya que proseguiría gloriosamente por la senda de su brillante destino.

Antes de conducir a sus lectores de la Presse Industrielle al notable salón central, el periodista anunciaba que echaría una mirada al pasado de México, gesta dolorosa por lograr su nacionalidad, y asimismo a su presente, a su prosperidad conquistada con nobleza.

Atisbo, hay que decirlo, comprensivo y cncomiástico.

Así podremos ver lo que puede hacer un pucblo, a pesar de todos los obstáculos, las pruebas y los reveses y la vitalidad sostenicla por la constancia y el patriotismo unidos al trabajo

El Siglo no sólo publicó ese día 9 de agosto "La República de los Estados Unidos Mexicanos en la Exposición Univcrsal", sino, también, la crítica de Ernesto García Ladevesse "La Exposición de París. La Pintura AustriacaHúngara y la Alemana" que, por su interés se incluye en el Documento número 6.

En esta crítica García Ladevesse analiza los cuadros que el imperio austro-húngaro exhibían en el Palacio de Bellas Artes, señala los aciertos y fallas de los pintores Brozic, Munkaczy, Payer, Hynais, asimismo examina los cuadros más notables de la sección alemana, los de Kuchl, Liebermann y Menzel. 
García Ladevesse al detenerse en el cuadro de Munkaczy, "Cristo ante Pilatos" apunta:

...es la tan ponderada figura de Cristo lo que nos seduce, no porque desconozcamos que la figura está hecha de un modo admirable, sino porque está mal concebida, Munkaczy da a su Cristo ante Pilatos una fisonomía en extremo vulgar; es dificil acostumbrarse a la idea de que el fundador de una religión tan grande tuviese tan simple y banal aspecto como le da el artista.

Hago esta cita de García Ladevesse pues encuentro que el pintor Miguel Munkaczy era ya, antes de 1889 , bien conocido en México, por las fotografías de su cuadro "Jesús en presencia de Pilatos", como se comprueba en una carta que el periódico La Voz de México el 11 de junio de 1882, insertó en su "Miscelánea" con el título de "Bellísima fotografia" ${ }^{8}$ Prueba también de que en México se estaba al tanto del movimiento pictórico de Europa.

El 10 de agosto El Siglo continuó con la publicación de "La República de los Estados Unidos Mexicanos en la Exposición Universal. Bosquejo histórico", en donde Montmayeur hacía un breve repaso de la historia de México desde su pasado indígena, la Conquista, la Independencia y la República hasta el momento en que, restablecida la calma, después de las guerras intestinas que impidieron el progreso, México vuelto al trabajo, consecuencia de la paz, conquistaba un lugar prominente entre las naciones civilizadas, revelando con justa y legítima complacencia las riquezas de su suelo y los magníficos productos de su industria.

Recalca Montmayeur la bonancible situación de México bajo el régimen de Porfirio Díaz, que al consolidar la paz permitía el desarrollo del país en el campo económico y cultural:

así ha logrado México mostrar al mundo —el último sábado- no sólo sus

${ }^{8}$ La carta dirigida el 5 de junio de 1882 a los redactores de La Voz de México dice: Muy señores míos: La circunstancia de haberse recibido en esta capital, un número insignificante de estampas fotográficas tomadas del gran cuadro del pintor austriaco Munkaczy, "Jesús en presencia de Pilatos", me sugirió la idea de reproducir una de ellas en la mira de que en caso de no salirme defectuosa proporcionar a mis conciudadanos, de manera poco dispendiosa, la sorprendente composicion de aquel joven y grande ar tista que ha tenido la honda y verdadera sensación en el mundo artístico, y de ver a las potencias curopeas disputarse la adquisición de su cuadro, sobre el cual declaró el gobierno francés que no saldría de su poder, fuera cual fuera la cantidad en que se le apreciara. Creo haber conseguido el objeto que me propuse según podrán juzgar Udes mismos por el ejemplar que tengo el gusto de acompañarles: pero si no es así, y Udes. encuentran defectos que yo no he advertido, les suplico se sirvan excusarlos y sólo el efecto con que se los dedica su afectísimo amigo y S. S. G. Miranda.

Los redactores de La Voz de México agradecieron el envío de la fotografía, "perfecta y digna de que la adquirieran cuantos deseen tener copia del magnífico original" 
recursos naturales y sus adelantos industriales, sino también sus adelantos morales y científicos, de los que quizá no se tenía una idea muy exacta.

El sucinto repaso histórico tenía como objeto preparar a sus lectores para

ver ese soberbio palacio azteca, en el que están acumuladas tantas riquezas.

$\mathrm{Y}$ ahora, lector amigo, vamos a recorrer sus diversos departamentos.

El Siglo el 13 de agosto incluyó "La Exposición de París. La pintura y escultura italianas de García Ladevesse", artículo en el que el crítico espanol ennumera y analiza la obra de pintores italianos, algunos muy inclinados como Carcano a cultivar "más que el arte la ciencia del paisaje" pues "el paisaje merece ser el género de pintura que más se cultiva al otro lado de los Alpes". (Documento número 7.)

El 13 de agosto El Siglo reanudó la publicación de "La República de los Estados Unidos Mexicanos en la Exposición Universal". En este artículo Montmayeur llevó a sus lectores, como había prometido a un recorrido por el palacio azteca. Dio comienzo con la visita al "Primer grupo - Bellas Artes.- Jefe: Señor José M. Velasco."

Aquí se encontraba, "una serie de obras magistrales, que demuestra que tanto la pintura histórica como el paisaje en particular tienen tiempo de haberse aclimatado en México". El guía no oculta su fervor por la pintura de historia,

son dignos de mención especial dos cuadros históricos llenos de movimiento y ejecutados por mano experta y fácil: "El senado de Tlaxcala en tiempos de Hernán Cortés" y "El cura Hidalgo" héroe de la Independencia, fusilado hacia 1811. En la última tela, sobre todo, se nota un dibujo de sorprendente vigor y los personajes históricos están agrupados con suma habilidad. La figura principal el cura Hidalgo a caballo se destaca con firmeza atrayendo sobre sí, desde luego, toda la atención.

Pero la alabanza de Montmayeur se desborda ante el hechizo, la prodigiosa novedad de los paisajes de José María Velasco, lección sublime sobre la geografía y la naturaleza mexicanas.

Los paisajes son los que dominan en la colección, debiéndose la mayor parte de ellos al pincel de Velasco, jefe del grupo; son encantadores, de un colorido cálido y de una profundidad maravillosa; citaremos entre otras, la vista del "Valle de México", en la cual se perfila el Popocatépetl sobre el horizonte; el "Arbol de la Noche triste" y el "Pico de Orizaba".

Parece que no contento el $\mathrm{Sr}$. Velasco con pintur bien se propuso pintar mucho, pues en la Exposición figuran nada menos que sesenta y cinco telas suyas 
Una visita al departamento que nos ocupa equivale a una excursión por los sitios más agrestes y pintorescos de México. Ahí pueden espaciarse los ojos por praderas inmensas esmaltadas con brillante colorido; ahí se despierta el deseo de ir a habitar en tan deliciosas comarcas, en las cuales los picos abruptos de las montañas dentelladas se pierden entre las nubes, mientras que al pie de aquellos colosos de pórfido y granito se deslizan las ondas cristalinas y mansas de los riachuelos en cuyas márgenes pastan en completa libertad numerosos ganados. El señor Velasco es un pintor distinguidísimo, dotado de incontestable talento Basta ver muchos de sus cuadros para darse cuenta que no solamente su pincel es fértil, sino que además es fuerte, es enérgico, es original, es grandioso.

Como Cahun, también Montmayeur no puede menos que rendir pleitesía al sabio, majestuoso y poético arte paisajístico de José María Velasco; su emoción y asombro se resumen en una trinca de muy atinados y rotundos adjetivos: enérgico, original, grandioso.

Montmayeur registra cuanto hay en los siguientes grupos: SegundoInstrucción pública: anatomía, mapas, aves disecadas, colecciones de coleópteros. Tercero - Ornamentación y Menaje, aquí celebra las colecciones de ónix, la magnífica cruz de Tecali, que atraía todas las miradas, los dos soberbios échantillons, "el buffet para comedor admirablemente ejecutado en puro estilo azteca que es, como se sabe, un verdadero recurso para la parte decorativa de los muebles". Cuarto.- Tejidos indígenas - Trabajos Manuales. - Bordados.

El 14 de agosto pasa revista a los grupos: Quinto - Productos naturales - Sexto - Industria, máquinas. Ferrocarriles - Artillería - Séptimo-Alimentación.

El 15 de ese mes se termina el recorrido con la visita a los grupos. Octavo - Agricultura - Noveno - Horticultura y Floricultura. Este último grupo uno de los atractivos de la Exposición con sus plantas raras y peculiares de México,

..espléndidas y originales muestras de la flora de aquel país, desde el espinoso "cactus" hasta las flores de perfumados efluvios, todo concurre para hacer de esta sección un trasunto del Paraíso terrestre, en el cual, la Naturaleza se hubiera metamorfoseado en bellísimas transformaciones a fin de deleitar.

Montemayeur al concluir la visita del Pabellón Mexicano, declara sentirse satisfecho por haber cumplido con su deber dando a conocer a franceses y mexicanos las excelencias de la Exposición Mexicana. El elogio, a decir verdad, queda muy por debajo de la realidad, pues todo lo exhibido por México ya curioso, ya práctico o útil, alcanza la valía de una significación histórica, una enseñanza y una moral.

México, gloriosa República por sus muchas virtudes morales - senten- 
cia Montemayeur - tierra fértil en abnegación e ideas, seguiría por siempre en el camino marcado por la naturaleza, y mantendría también por siempre alto y firmemente el "pabellón del Progreso, genio de los pueblos".

El Mundo el 15 de agosto en "Pintura en París. Honor a un mexicano", decía tomar de La Phaire de la Loire el juicio del ilustrado crítico Francis Leon Satin sobre José María Velasco. El Mundo suprime las opiniones acerca de la pintura histórica y se circunscribe a la opinión sobre Velasco.

Estos párrafos adjudicados a Satin en traducción de El Mundo, son exactamente los mismos escritos por Leon Cahun, publicados con anterioridad por El Nacional de 6 de agosto y reproducidos por El Monitor Republicano y El Siglo Diez y Nueve el 7 de agosto.

¿Quién es en verdad el autor? Me inclino por Leon Cahun, ya que sus apreciaciones acerca de José María Velasco - como se ha visto-corresponden a una secuencia de pensamiento y de exposición, están dentro de ese agudo panorama que traza de México, en especial de sus tradiciones, de su identidad y expresión artística. En cambio los párrafos atribuidos a Satin están sueltos, fuera de contexto, simplemente El Mundo asegura que están tomados del periódico La Phaire de Loire, donde aparece publicado el de Leon Cahun. ${ }^{9}$

Juan de Dios Peza en Memorias, religiosas y retratos, (1900) "José María Velasco", reconoce a Cahun como autor del artículo pues dice: "Leon Cahun, el gran crítico de arte ha hecho un hermoso juicio de las obras de Velasco en la Exposición de París".

El Nacional el 21 de agosto en "El Pabellón Mexicano" traducía del South American Journal de Londres la visita que el reportero de este diario hiciera a nuestro pabellón, guiado por el comisario de México, Manuel Díaz Mimiaga. Lo primero que menciona el visitante es el edificio ideado por Antonio Peñafiel y ejecutado por Antonio M. Anza, con un costo de dos

\footnotetext{
${ }^{9} J$ ustino Fernández en su obra El Hombre Estética del Arte Moderno y Contemporáneo, México, UNAM, Instituto de Investigaciones Estéticas. 1962, pp. 171-172 hace esta cita de Satin. "En París, en 1889, para el crítico Satin [Velasco] fue una revelación y dijo que era distinto de Corot y Rousseau, pero no menos sincero; encontró el encanto y la rareza de los sitios que pintó Velasco y un verdadero pintor original."

Ida Rodríguez en su indispensable obra La Crítica de arte en el siglo XIX Documento III (1879-1903) México, UNAM, Instituto de Investigaciones Estéticas, 1964, pp. 235-236, registra "La pintura en París. Honor a un mexicano". El Mundo, México, jueves 15 de agosto de 1889.

Fausto Ramírez en "Acotaciones iconográficas a la Evaluación de episodios y localidades en los paisajes de José María Velasco", José Marín Velasco. Homenaje, México, UNAM, Instituto de Investigaciones Estéticas, 1989, dice que Ida Rodríguez recogió "una crítica interesante publicada originalmente en La Phaire de la Loire".
} 
millones de francos. Notifica las dimensiones, los materiales y la arquitectura que es, hasta donde es posible, representación del antiguo estilo azteca, y las esculturas que le adornan simbolizan la mitología de aquel pueblo.

Más adelante dice que en el salón central se podía admirar una hermosa reproducción de pinturas al óleo representando paisajes y sucesos de la historia de México. Aunque da razón de las artesanías y de otros objetos que se exhiben en las vitrinas, el inglés se muestra más interesado en los recursos materiales cuya abundancia hacían de México uno de los países más ricos de la tierra; de aquí que resultara inadmisible el que Inglaterra hubiera permitido que otros le llevaran la ventaja en aquel mercado. Esperaba que la Exposición Mexicana despertara el espíritu de empresa de los ingleses y que tuviera mayor interés en el mercado azteca.

El 21 de agosto El Nacional, publicó "Fuera del país. El pabellón de la República Mexicana en la Exposición Universal de 1889. Traducido de La Nature de París de 6 de julio." La colaboración la firma Max de Nansouly.

El autor comenzaba recomendando a los visitantes de la Exposición de 1889 que examinaran con detenimiento especial el pabellón de la República mexicana, edificado en el Campo de Marte pues no era "una obra banal ni como continente ni como contenido", pues los mexicanos habían construido un pabellón que presentaba, por sí mismo, un interés arqueológico y nacional. El arquitecto Antonio M. Anza y el sabio arqueólogo Antonio Peñafiel habían sabido interpretar la idea de los organizadores.

De la arquitectura indígena - comenta Nansouly - si no se habían leído las obras de Batissier, Humboldt, Lenoir, Husson, Kingborough y Dupaix, se conocería bien poco. Las artes habían llegado a su máximo esplendor en la antigua Tenochtitlan, capital del imperio mexicano, cuando la furia guerrera de Cortés y sus soldados y el ciclo evangélico de los misioneros redujeron a la nada la civilización azteca. No había quedado en pie un sólo monumento, por lo tanto, era aún más meritoria la reconstrucción de Peñafiel y Anza basada en fragmentos y antiguas tradiciones.

A seguidas Nansouly describe pormenorizadamente el pabellón de México que se distingue por su aspecto original, el de su templo en el que no hay más aberturas que las puertas de entrada y toda la luz la recibe el interior de los patios, tiene dos pisos y se compone de una gran galería central y dos laterales que sobresalen en la fachada del edificio:

El plano interior de las paredes está inclinado, de manera que da al conjunto de la habitación la forma piramidal que predomina en todas las arquitecturas primitivas y se ve en las cabañas, los sepulcros y los altares. Como material se han empleado grandes piedras alineadas horizontalmente $y$ 
adornos decorativos coronados de almenas como los que se ven en los edificios moriscos.

El edificio tiene azotea.

La decoración principal de la fachada consiste en bajos relieves que representan reyes, divinidades y diversos atributos que simbolizan las artes y la industria.

Nansouly elucida el porqué el edificio semeja un templo. Entre los antiguos mexicanos, como entre todos los pueblos primitivos, el templo era el monumento principal y los sacerdotes se significaban por ser verdaderos pozos de ciencia. La sabiduría sacerdotal de los aztecas en el campo astronómico estaba más adelantada que la de los romanos en tiempo de Julio César y en la Europa de Francisco I. Los sacerdotes aztecas tenían profundos conocimientos sobre el movimiento de los planetas y supieron fijar con exactitud la época de la fiesta del fuego que se celebraba cada cuatro años, "el ilustre Laplace al examinar sus cálculos únicamente encontró un error de once minutos".

Tomando en cuenta la importancia de los templos, Antonio Peñafiel y Antonio Anza se inclinaron por la construcción de un vasto templo, en el que, según Nansouly se integraron figuras genuinas encontradas en recientes descubrimientos arqueológicos.

... En el basamento se apoya un pórtico sostenido por figuras auténticas descubiertas en Tula por el Sr., Peñafiel; una connisa de origen igualmente auténtico, procedente de Xochimilco, corona ese pórtico

Nansouly hace mención de las puertas del edificio situadas en las paredes laterales, adornadas de atributos representando los solsticios y equinoccios, los adornos estaban rodeados de cañas con espigas de maíz, las que indicaban la fecha de la reforma del calendario azteca.

En el primer piso se encontraban una serie de bajorrelieves, los que a Nansouly le parecieron muy "curiosos", ejecutados por el escultor mexicano Jesús Contreras.

En el pabellón de la derecha se ve a la diosa Centeoll, la Ceres mexicana, con los brazos cargados de mazorcas de maíz, Tlaloc, el dios de las lluvias, de las nubes y de las tempestades, que con una mano lanza las terribles inundaciones de la región mexicana y con la otra los rayos; junto a él Chalchiuhtlicue la diosa de las aguas regularizadas y benéficas.

En el pabellón izquierdo están Xochiquetzal, la diosa de las artes, con las manos llenas de flores; Camaxtli el dios de la caza y el dios del comercio Yacatecuhtli.

Los seis bajo-rrelieves del pabellón central representan a los reyes y caudillos que se distinguieron en la lucha contra los conquistadores de Cortés. 
Estos bajorrelieves, asegura, Nansouly, habían sido ejecutados siguiendo documentos auténticos y

.... presentan una originalidad artística absolutamente notable; resumen de todas las fases una curiosa civilización primitiva que desapareció en una catástrofe tremenda y sobre la cual han hecho investigaciones nuestros arqueólogos más notables.

$\mathrm{Ni}$ las almenas que se destacan en el fondo del techo, en la parte superior del edificio, tienen nada de vulgares: los originales fueron encontrados por el $\mathrm{Sr}$. Peñafiel en las cercanías de San Juan Teotihuacan.

Los constructores del pabellón de México, en concepto de Nansouly, realizaron su obra con habilidad consumada, supieron amalgamar la arquitectura prehispánica con los materiales más modernos: el hierro, el bronce y el acero.

El armazón del edificio de hierro aparente salido de los talleres parisinos de Cail, había sido tan bien utilizado que no se rompía la impresión de una restauración arqueológica exacta, tanto que si Nezahualcóyotl resucitara creería hallarse en su tiempo.

Nansouly no captó del todo la grandeza de la civilización del México antiguo, ya que la tilda de "curiosa", aunque digna del aprecio de los arqueólogos franceses. Su artículo es en general lisonjero para el singular pabellón de México, así como para sus constructores y organizadores de la Exposición Mexicana, cuyos esfuerzos

.. han sido coronados por un éxito brillante y harán verdadero honor a su país: esta es la feliz. conclusión que se desprende de su examen

El Siglo el 21 de agosto, consignó "La Exposición de París. La pintura inglesa", crítica de García Ladevesse. El corresponsal decía que era en la sección inglesa donde había que admirar "la más perfecta maravilla de relieve y colorido que conticnen las secciones extranjeras del Palacio de Bellas Artes".

García Ladevesse se dedica principalmente a la pintura de Lawrence, Alma Tadema, obra que mucho alaba por sus temas clásicos por ese mundo griego que recrea. Asimismo se interesa por los cuadros de Leighton, los que celebra por su composición y la ligereza que da a sus figuras femeninas.

No deja de lado a Leader al que incorpora a la novedosa escuela de los impresionistas.

También se aplica a la obra de los retratistas W. E. Glastone y Herkomer y, desde luego, a los acuarelistas "cuya obra ocupa grande espacio en la sección de pintura inglesa", (Documento número 8.) 
El Nacional el 29 de agosto en "Los pintores premiados en la Exposición de París" daba a conocer la lista de los premiados con las medallas de honor en la sección de pinturas de la Exposición Universal de 1889. El país anfitrión se había quedado con doce y cedido dieciocho a los trece países con representación pictórica en el gran certamen.

El reparto de los premios ha sido en esta forma.

Francia: Mres. Dagnau-Bouveret, Delaunay, Dupré, Aimé Morot, Lhermitte, Gigouse, Hebert, Bernier, Cormon, Detaille, Lefbvre y Collin.

Alemania: Liebermann y Ukde.

Inglaterra: Alma Tadena y Moore

Bélgica: Stevens, Courtens y Wanters.

Estados Unidos: Sargent y Melchers.

Holanda: Israels.

Italia: Boldini.

Dinamarca: Kröyer.

Noruega: Wewensjold

Suecia: Bergh.

Finlandia: Edelfeldt

Rusia: Chelmonski

Austria: Munckaczy

El articulista, sin duda español, manifiesta su disgusto debido a que a España sólo se le había otorgado una medalla, lo mismo que a Finlandia, en cambio, a los Estados Unidos, nación en la que no abundaban aún los artistas de gran categoría artística, se le habían concedido más premios que a España Ciertamente que la Península no podía competir en las mil ramas de la ciencia y la industria con los países más industrializados, pero en pintura no le iba a la zaga a ningún país, y para prueba descollaban en la sección española.

"La rendición de Granada", de Pradilla, "La conversión del duque de Gandía", de Moreno Carbonero; "El fusilamiento de Torrijos", de Gisbert; y de otros de notorio mérito; además de "La silla de Felipe II" de Jiménez de Aranda y los retratos de Raimundo Madrazo.

A propósito - se lee en el artículo- un periódico de Madrid, ante la parcialidad del jurado, revelaba su desencanto,

.... ninguna de las grandes y hermosas páginas de nuestra pintura histórica expuestas en el Campo de Marte ha sido premiada

El periódico madrileño añadía que lo mismo había sucedido en 1878 , con "La Juana la Loca" de Pradilla, pero en el caso de la Exposición de París de 1889 - le comunicaba confidencialmente un amigo ni artista ni escritor 
que no estaban exentos de culpa los españoles- pues en la sección española del Concurso sólo estaban bien colocados los pintores allí presentes y establecidos en París

.... los mismos propuestos ahora para premios.

¿Si se regirá en la sección española de la Exposición Universal por estar en

Francia, el adagio francés Les absents ont toujours torti?

España, no tuvo suerte en la Exposición Universal con su obra pictórica, pero tampoco con su pabellón. "En España en la Exposición de París" ( $E l$ Siglo Diez y Nueve, 23 de julio de 1889) un periódico español censuraba a los responsables de la construcción del pabellón, pues en tanto el de México llamaba poderosamente la atención, el de España, pese a su elevado costo 250,000 pesetas, adcmás de 20,000 para el arquitécto Mélida y unos picos más, era "un edificio o barrancón de madera vieja pintada de azul que más parece digna de una menagerie que para lo que debe servir".

¿Fueron premiados los pintores mexicanos?

México fue aún menos afortunado que España, nuestros pintores no expusieron en Palacio de Bellas Artes, tal nos hace saber Luis Islas García.

El papel de México y la Amćrica Iatina en general, no había sido muy brillante en París: ni siquiera en el Palacio de Bellas Artes expusieron, y por un momento pareció que el jurado no calificaría. Por fin, rápidamente, a instancias de México, recorrió las galerías americanas y otorgó los premios, que no llegaron a diez: alguna medalla de plata de segunda clase.

Contrariamente al arrebato del periódico español, José María Velasco encargado de la sección artística, tomó con serena calma el no haber sido premiados los mexicanos.

Si los jurados franceses se mostraron inflexibles respecto a sus propios paisanos, no encuentro razón para que respecto a nosotros se tuviese la consideración suficiente para discernir premios que no merccieran nuestros artistas. Los jurados extranjeros (México no tuvo representante en el jurado) habrán trabajado en beneficio de sus propios páses y tampoco encuentro motivo para que se inclinaran a nuestro lado."

El Siglo el 30 de agosto publicó una carta de Ernesto García Ladevesse en la que daba cuenta de la visita al pabellón de México del Shah de Persia,

${ }^{10}$ Islas García, $O p$ cit., p. 44 .
${ }^{11}$ Idem. 
Nasser-Ed-Din. El Shah no dejó de alabar la arquitectura original del palacio mexicano.

El 13 de septiembre El Siglo incluía el artículo "En la Exposición. El Palacio Mexicano. El edificio y sus dimensiones -Una de las más curiosas exposiciones del Nuevo Mundo - El país de los Aztecas. - Textiles y pájaros moscas. (De La Lanterne, de París, del 17 de agosto de 1889)."

No es una hipérbole - afirmaba La Lanterne - dar el nombre de palacio a la imponente construcción que México había levantado en el Campo de Marte para la exhibición de sus productos.

Hacía hincapié el periódico en el porvenir que en México esperaba a los constructores de maquinaria franceses, dado que, en ese país, se carecía de esa industria. Esa era una de tantas razones que lo incitaban a pasar revista "a esa brillante y curiosísima exposición".

La Lanterne describía con todo detalle el palacio mexicano, precisaba sus dimensiones, la escalera de dos alas que daba acceso a las galerías superiores, la iluminación muy bien lograda.

Su estilo es tan original que se le consideraba incomprensible, estaba inspirado en los antiguos edificios aztecas. Recordaba los mejores y bellos tiempos de la antigua civilización contemporánea de los Incas y no se debía olvidar que México y Perú tenían artes y un estado social muy adelantados, desde mucho tiempo antes de la llegada de Hernán Cortés y Francisco Pizarro, los que impusieron en esas hermosas comarcas las costumbres y el estado social español.

La Lanterne explicaba que el centro del palacio mexicano estaba consagrado al culto y simbolizalsa la religión del sol y del fuego.

Un gran zócalo presenta en su parte inferior las insignias de ese culto, y en su parte superior los braceros simbólicos de sus fiestas periódicas

Una sucesión de gradas carácter principal de los antiguos templos aztecas, conduce al pórtico, en el que se encuentran dos cariátides. El pórtico tiene un coronamiento el símbolo del Sol-Tonatiuh presidiendo a la creación de Cipaclli que representa la fuerza fertilizadora de la Tierra, nodriza del género humano.

Para La Lanterne la mitología mexicana resultaba excesivamente complicada, lo que podía comprobarse visitando el palacio, por lo mismo, daba los nombres de las divinidades aztecas, nombres y atributos desconocidos aún por los estudiosos de las religiones antiguas; pormenorizaba las divinidades que figuraban en el edificio, así como los grupos que representaban a la antigua historia mexicana en sus ctapas brillantísimas. En uno de los grupos se hallaba el rey Izcoatl, el fundador de la nacionalidad 
y monarquía mexicanas. Y en el otro Cacama, el heroico defensor de México; Cuitláhuac, el héroe vencedor de Hernán Cortés y Cuauhtémoc el último emperador de México.

Estos personajes —añadía La Lanterne-cuyos nombres parecían tan raros, eran, sin embargo, muy populares y bienquistos en México, estaban siempre presentes, "cada nueva generación les daba nuevo contingente de poetas e historiadores".

Por último el periódico pragmáticamente y con miras colonialistas, enumeraba a sus lectores los productos de "aquel país admirable, que es -por decirlo así- un país nuevo, un pais por explotar".

El 14 de septiembre El Siglo en "La Exposición Universal de París" tomaba de un periódico español, algunos valiosos pareceres sobre la Exposición Mexicana, en los que el diario hispano reiteraba lo dicho en una de las primeras cartas: el pabellón cle México era uno de los más notables construido por las Repúblicas americanas, tanto por sus dimensiones como por su recio carácter artístico y arquitectónico que lo distinguían de los demás pabellones y lo hacían digno de estudio,

... es uno de los pocos edificios que hay en el Campo de Marte que tienen arquitectura propia y que representan, no sólo una escuela determinada, sino es lo que podríamos llamar la parte histórica de las construcciones de un país: las cariátides, las pilastras, los frisos, las cornisas, las grecas, los pórticos todo conserva un estilo y un carácter para estudiar la arquitectura mexicana.

Y aún más ese edificio guardaba cierta semejanza con el arte griego: la particularidad de buscar la belleza por medio de las líneas rectas.

Los grupos mitológicos eran también notablísimos, y todo visitante a la Exposición podía comprobar que el pabellón de México, era de los que más llamaba la atención del público.

Los mexicanos se habían hecho acreedores a muchos aplausos,

.... porque si en el edificio han estádo acertados en la clasificación de los productos y en la calidad de los que han expuesto, pueden y deben estar satisfechos de su obra.

Le Trait d'Union Joumal franģais de Mexico, el 19 de octubre publicó "Le Mexique a L'Exposition. Listcdes récompenses distribuées aux Exposants Mexicains Le 29 setembre $1889 . "$

Le Trait d'Union ponía en claro que la lista oficial de los premios otorgados a los expositores mexicanos la había recibido esa mañana, y por lo mismo, sólo se ocuparía de lo referente a México y eso, sin comentarios, ya que debía recorrer en las listas treinta y tres mil premios para sacar los 
nombres que se le habían proporcionado ese día. Muchos habían sido los premios concedidos a México, algunos de muy alta categoría. El periódico expresaba su reconocimiento a los organizadores de la Exposición Mexicana, y sus felicitaciones al presidente Porfirio Díaz y al general Carlos Pacheco.

\section{OBRAS DE ARTE}

Primera clase: pinturas al óleo.

Diversas pinturas y dibujos.

Medalla de plata. Velasco.

Medallas de bronce. Belmonte y José Jara

Mención honorífica. Bribiesca

Tercera clase: Esculturas y grabados en medallas

Medalla de plata. Guerra.

Medalla de bronce. Contreras

Cuarta clase: Diseños y modelos de arquitectura

Mención honorifica. Anzorena y Agreda, Enrique Barrados y I.uis Molina.

¿El pabellón mexicano, tan alabado, tan ponderado mereció algún premio? Sí. El Comité de Premiación

... otorgó al Gobierno mexicano uno de los Grandes Prix de la Exposición en el grupo y clase de correspondientes (Grupo Cuarto, Clase 63). Además concedió medallas de oro a los autores del proyecto, Anza y Peñafiel; medalla de plata a Jesús $F$ Contreras, y otras preseas a constructores y colaboradores

El juicio del Comité de Premiación integrado por "varios ingenieros y arquitectos, ... presididos por el mismo señor Alphand, Director de Trabajos Públicos", fue "favorable y satisfactorio". Elogiaron "expresivamente... el indisputable mérito del edificio, así como el talento y conocimientos especia* les tanto de nuestro distinguido ingeniero señor Don Antonio Peñafiel". ${ }^{12}$

El 24 de octubre El Siglo publicó "Mćxico en el Campo Marte de La Nation del 25 de agosto de 1889 . Traduciclo para el Siglo XIX". En este artículo se afirmaba que todos los colegas de la prensa parisiense unánimemente hacían constar el gran éxito alcanzado por la Exposición mexicana, no sólo por la belleza y originalidad de su edificio, sino por la variedad y riqueza de los productos expuestos, pues no había en el mundo entero otro país con el cual la naturaleza se hubiese mostrado tan generosa, ni había otro que brindara mayores recursos a la actividad humana. Tampoco había otro país en América que ofreciera a capitalistas, industriales, estadistas, mayores garantías de seguridad y pingüies utilidades, los franceses debían hacer caso omiso del

${ }^{12}$ Ramírez, Op cit, p. 214 
descrédito que envolvía a México, asegurarse una situación comercial, echar por la borda añejas preocupaciones y adoptar el lema americano: iGo ahead!

El Siglo el 31 de octubre en "La Exposición. El pabellón de México. -Un país rico y bellísimo-. El México de hoy", tomaba del XIXe Siècle de París del 12 de octubre de 1889 estas significativas líneas alusivas a los premios obtenidos por México,

...los sacrificios hechos por el gobierno mexicano para figurar dignamente en la Exposición Universal de 1889, han sido ampliamente recompensados. Diez diplomas de honor, numerosas medallas de oro, plata y de bronce han afirmado el éxito de la participación, que esta joven y grande República latina ha tomado en el certamen internacional del Campo de Marte

El diario parisino se hacía eco de lo asentado por La Nation, acerca de la opulencia de México y porfiaba en lo necesario que era para Francia el conocer a fondo a México, con el propósito de establecer a la mayor brevedad posible un activo comercio.

El Siglo el 8 de noviembre traducía de Le Trait d'Union esta nota con el título "La Legión dè honor en México".

Con la más viva satisfacción acabamos de saber que a propuesta del Sr. Conde de Saint Foix, Ministro de Francia en México, los señores Lic. Manuel Romero Rubio, Ministro de Gobernación, General D. Carlos Pacheco, Ministro de Fomento y D Manuel Díaz Mimiaga, Comisario general de México en la Exposición Universal han sido promovidos al grado de comendadores de la orden de la Legión de honor.

Asimismo habían sido acordadas las Cruces de caballero para el pintor José María Velasco y para Antonio Anza, el arquitecto del pabellón mexicano en la Exposición de París.

José María Velasco en su correspondencia dirigida a su esposa el 8 de noviembre mostró su satisfacción por este reconocimiento. ${ }^{13}$

El 6 de diciembre El Siglo notificaba la clausura de la Exposición Universal de 1889 .

Las Exposiciones Universales tenían como meta la exhibición de los frutos de la paz, del trabajo y de la industria, propiciar el comercio, al que se le veía como senda segura para el progreso, la libertad y la civilización; atadura y base del entendimicnto entre los pueblos, en una de las Exposiciones más importantes, la de 1889, México logró varios de los objetivos que se propuso al concurrir a ese certamen.

13 Islas García, p. 13 
En primer lugar, ante los ojos del mundo entero nuestro país echó por tierra las calumnias tejidas en su contra y las que por tantos años oscurecieron su imagen; demostró y, con creces, que era una nación civilizada con una ancestral e imponente cultura, con un progreso intelectual, artístico y material, y por lo mismo, digna de pertenecer al consorcio de las naciones civilizadas. En esta ocasión México tuvo la oportunidad de decirle a voces a Europa que, como ella, tenía tanto ser histórico.

Como muchas veces lo repitió la prensa en París, se consideró a México como un país fabulosamente rico en recursos naturales, productivo, en pleno desarrollo, industrial, económico, comercial y cultural, que garantizaba plenamente la inversión por su futuro de grandeza y prosperidad atesorados en su vasto territorio. País en el cual sin perder un momento se debería comerciar, y darle el prestigioso lugar que se merecía entre todas las naciones.

En el campo cultural y artístico los paisajes de José María Velasco fueron muy admirados, atrajeron poderosamente el interés de la crítica europea, se le señaló como uno de los grandes exponentes de un arte nutrido en los veneros de su tierra, arte original y nacional, y al ser comparado con los grandes artistas franceses - aunque no se dijera-se le reconoció como un pintor de categoría universal, jerarquía que hoy no se le discute.

México con su pabellón de arquitectura y ornamentación sustentadas en lo prehispánico, tornó orgullosamente su vista hacia ese esplendoroso pasado y manifestó ante el mundo que, al recuperar sus valores, enriquecía su conciencia histórica para fortalecer con un perfil propio, su identidad nacional y, también, como el tiempo a poco andar lo confirmaría, su aportación y enriquecimiento al arte, su universalidad.

El pabellón mexicano como lo patentiza la reiterada atención periodística causó por su originalidad sorpresa, no se le negó belleza, ni monumentalidad, se le acercó al arte griego, y aunque en ese entonces el arte del pabellón mexicano fue considerado "curioso", "raro", "extraño", "exótico" y su representación plástica fantaseosa, no obstante, constituyó la ancha y espaciosa puerta que se abrió para el conocimiento del arte indígena, arte que en este nuestro siglo XX ha sido y sigue siendo exhibido, admirado, ensalzado en los más renombrados museos de las grandes capitales del mundo. Estudiado hoy día por propios y extraños, el arte prehispánico ha dejado de ser un arte exótico para integrarse por su altísima categoría al arte universal.

México, como refrenda el repertorio periodístico aquí anotado, obtuvo honra, respeto y salió victorioso en la prueba que fue la Exposición Universal de 1889 . 
DOCUMENTO No. 1

\title{
EXPOSICIÓN INTERNACIONAL EN PARÍS
}

\author{
PROYECTO DE EDIFICIO \\ PARA EL DEPARTAMENTO MEXICANO EN LA EXPOSICIÓN DE PARÍS
}

"Comisión para formar un proyecto de edificio para la Exposición Internacional de París".

Señor Secretario de Fomento:

En cumplimiento de la órden que se sirvió vd. comunicarme con fecha 16 de Febrero pasado, para que en unión del Sr ingeniero Antonio M. Anza, procediera á formar un proyecto de edificio para el departamento mexicano en la próxima Exposición Internacional de París, tengo la honra de proponer á vd. ese proyecto, en que hemos querido representar, conforme á los deseos de vd., una construcción de carácter exclusivamente mexicano.

Este trabajo debía comprender dos partes esenciales: la construcción adecuada al objeto á que se destina, y la forma que pudiera contener los rasgos principales que caracterizan nuestros monumentos y nuestra historia nacional.

Para este fin se necesitaban modelos para la forma y materiales de ornamentación que tuvimos que tomar, en su mayor parte en mi obra inédita titulada: "Monumentos del Arte Mexicano Antiguo"

Me ocuparé en primer lugar de la descripción del edificio, y en seguida, de su representación simbólica y ornamental.

El edificio mide 70 metros de largo por 30 de ancho, y de altura $14 \mathrm{~m} 50$ hasta las almenas; se compone de un salón central de 40 metros de largo por 24 de ancho, en cuyos lados menores se apoyan dos pabellones de la misma forma, de $23 \mathrm{~m} .80$ por $12 \mathrm{~m} .40$.

Una escalera de dobles rampas colocada en el centro del gran salón, da acceso á las galerías que forman el segundo piso. Con esta disposición hemos creído satisfacer las necesidades que tiene que llenar un edificio de esta naturaleza, destinadoá contener colecciones de obras de arte, productos naturales y objetos de industria: puede considerársele como un museo, compuesto de grandes salas en donde se pueda abarcar desde un lugar el conjunto de los objetos contenidos en el edificio. Para este fin debe tener grande extensión mural, que facilite la colocación de los objetos que hay que exhibir, y estar iluminado de un modo uniforme, sin que se produzcan ni sombras ni reflejos que perjudiquen la vista de los mismos objetos: esto último se ha conseguido con la luz cenital que penetrará por los tragaluces practicados en estas salas.

La cantidad de luz que tiene el edificio es abundantísima, si se tiene en cuenta que para salas bien iluminadas por luces laterales, en que los claros no reciben sino la luz difusa, la relación de la superficie de estos claros á la de la sala debe ser de lá 5 . El salón central tiene un tragaluz de 30 metros por $13 \mathrm{~m}$, lo que da una superficie de 390 metros cuadrados, y la sala tiene 40 metros por $24 \mathrm{~m}$, ó sean 960 metros cuadrados, es decir, en relación de 1 á 3; en las salas laterales los tragaluces tienen $19 \mathrm{~m} .70$ por $4 \mathrm{~m} .80$, ó sean $94 \mathrm{~m} .56$ metros cuadrados y tienen una superficie de $23 \mathrm{~m} .80$ por $12 \mathrm{~m} .40$ que dan $295 \mathrm{~m}$. 12 cuadrados ó la 
relación de 1 á 3 12. Hay que tener presente que esta luz es directa y no difusa, de modo que podemos asegurar que estas salas del edificio reciben doble cantidad de luz de la que necesitan las que deben estar mejor iluminadas

Dos grandes puertas colocadas en los pabellones laterales, servirán una para la entrada y otra para la salida de los visitantes á la Exposición. Con una línea adecuada, trazada de carmín, se indica en las plantas el trayecto que deben recorrer los visitantes, de modo que puedan observar todos los objetos expuestos en los salones subir y bajar al segundo piso por escaleras independientes, sin que en todo el trayecto puedan formarse corrientes encontradas de los mismos visitantes.

Dos elevadores colocados á là entrada y á la salida servirán para làs personas que quieran visitar las galerías de la parte alta sin molestarse en subir las escaleras.

Van marcados en las plantas los lugares destinados á los nueve grupos en que se há dividido la Exposición Internacional, sin señalarles colocación especial, para que según los elementos de que dispongan, así puedan ocupar un lugar más ó ménos extenso.

El edificio deberá ser metálico en su mayor parte, puesto que se quiere desmontar y transportarse más tarde á Méxíco, pudiendo utilizarse, si el gobierno lo cree adecuado para instalar en él un Museo Arqueológico.

En la construcción hemos procurado conciliar la solidez con la economía en los gastos. Una serie de bastidores triangulares, de toda la altura, y formados de fierro, en $T$ correspondiendo con las columnas de las galerías, vienen á formar el apoyo del revestimiento exterior que está en talud. Trabes metálicas ligando las columnas á los bastidores, y unas y otras entre sí, les darán la estabilidad necesaria y el apoyo suficiente á los pisos de las galerías altas. La cubierta de cada salón se apoya en grandes trabes horizontales, correspondiendo con las columnas que reciben á la vez la cubier ta metálica de las galerías altas y la serie de caballetes de tragaluces transversales, que forman el tragaluz total En estos hemos querido seguir una disposición semejante á la que ha empleado Paxton en Inglaterra para el Palacio de Cristal.

Formado así el esqueleto de la construcción, sólo falta agregar, que el revestimiento interior se formará con los mismos aparadores destinados á contener los objetos de la Exposición.

Llamamos muy expecialmente la atención de vd. sobre la decoración exterior que, aunque complicada, es en nuestro concepto de muy sencilla y fácil ejecución: no es preciso recurrir al fierro colado, ni por consiguiente á las grandes fundiciones de fierro, que necesitarían mucho tiempo para dar los materiales de la construcción del edificio

La lámina de fierro se presta mejor para hacer esta decoración, por su ligereza y mayor economía; con ella se revestiría todo el exterior apoyando las láminas sobre piezas transversales que se fijaran en los bastidores.

Decoraciones fundidas en zinc se colocarían en los lugares respectivos, asegurándolas sobre las láminas por medio de tornillos.

Habrá necesidad de otros pormenores de construcción que, para no alargar este informe, se presentarán oportunamente á la Secretaría.

La forma del edificio se ha tomado de la que tenían los antiguos teocalis aztecas, y el ornato que hemos empleado es de orígen puramente mexicano, 
de los dibujos de la obra citada de los «Monumentos del Arte Mexicano antiguo", ejecutados por los Sres. Domingo Carral, José H. Rovirosa y Julio Peñafil. También por medio de dibujos ó amoldados, hemos adquirido importante contingente de los ejemplares de mi colección arqueológica particular y de la muy valiosa del Museo Nacional.

Datos muy interesantes nos fueron suministrados, en lo que toca á la forma del edificio, del estudio que acabo de hacer al visitar el monumento de Xochicalco, del Estado de Morelos; monumento que por mi cuenta considero, en vista de sus signos cronográficos, como la mejor página perteneciente a la antigua civilización regional mexicana del pueblo tlahuica.

Como los templos han sido en lejanas épocas el verdadero resúmen del arte antiguo, de ellos debía tomarse el modelo, no sólo para representar la antigua religión, sino también la antigua historia nacional: dos asuntos que han formado, en todos tiempos la imágen fotográfica de todos los pueblos.

Podemos asegurar que, en el proyecto que tenemos la honra de presentar á vd., no hay adorno, ni símbolo, ni figura alegórica que no haya șido sacada auténticamente de la arqueología mexicana, y con la única mira de revivir la genuina civilización nacional

No hemos querido traspasar los límites de la arqueología mexicana; podrían haberse tomado de la rica y más abundante de Uxmal y Palenque mejores materiales; pero si bien hoy' Yucatán y Chiapas están en el mapa de México, no lo estuvo antes su originaria civilización que se extendía desde Tabasco, Chiapas y Yucatán, hasta los confines de la América Central y tal vez sin haber tenido contacto con la raza de orígen azteca.

El edificio se compone de una parte central y de dos pabellones laterales; la parte media, compendio del culto mexicano, resume la religión del sol y del fuego; allí se encuentra un gran basamento llevando en la parte inferior los signos de este culto, y en la superior los braseros simbólicos de sus festividades periódicas.

Una escalinata, principal carácter de los antiguos templos, conduce al pórti$\mathrm{co}$, en donde se encuentran dos cariátides, cuya forma fué tomada de un estudio arqueológico que hice recientemente á Tula, del Estado de Hidalgo, con el objeto de encontrar un sostén ó columna que pudiera tener aplicación á la arquitectura mexicana

Lleva por remate el pórtico el símboló del sol, Tonatiuh presidiendo la creación de Cipactli, representante de la fuerza fertilizadora de la tierra, que da alimento al genero humano.

Suntuoso templo tuvo el sol en una de las pirámides que hoy llevan el nombre de San Juan Teotihuacán. La tribu tolteca, madre de la Nación Mexicana, tenía por principal enseña la figura del astro: en el templo Mayor, ocupaba uno de los lugares principales; deidad creadorâ, se le llamaba, Ipalneomoani, por quien se vive, y sobre su imágen, la conocida figura de estrella, se dice que caía la sangre de los sacrificios humanos. La figura del sol se encuentra en la cara superior de esos monumentos que los mexicanos llamaban Cuauhxicalli, especie de obeliscos votivos ó cronológicos, como se usaron entre los caldeos ó fenicios; esa imágen se ve también sobre la pièdra de Tizoc, en otras piedras epigráficas conmemorativas, así como en la piedra del Calendario, monumento que ha dado á conocer al mundo científico con el 
nombre de Piedra del Sol, el ilustre historiador y distinguido poeta D Alfredo Chavero.

El Tonatiuh figuraba, finalmente, tanto en la Mitología como en las épocas cosmogónicas; formaba parte del pasado y del presente en la religión mexicana: por esto le hemos asignado preferente lugar en la parte más importante del edificio

El dios del fuego Huehueteolt, el dios antiguo por excelencia, recibía un culto universal de cuatro en cuatro años, de año en año y de cielo en cielo; período de 52 años en que se renovaba el fuego; la llama siempre encendida ardía en todos los templos como la lámpara perdurable de la religión. El culto del fuego estaba relacionado con la distribución del tiempo en el Calendario, y se adunaba de tal manera al del sol, que llegaron á confundirse entre los mexicanos, como en otros pueblos de América.

Para concertarlos con los fines de la Exposición Internacional, hemos colocado grupos mitológicos en los pabellones derecho é izquierdo del edificio; en el primero están las figuras de la diosa Centeotl, protectora de la agrícultura, llevando á la derecha á Tlaloc dios de las lluvias, y á su izquierda á Chalchiuhtlicue, diosa del agua; tres divinidades que según las antiguas creencias aztecas, daban vida á la humanidad y fertilidad á los campos.

En el pabellón izquierdo y en lugar simétrico, irán representados Xochiquetzal como deidad de las artes, Camaztli de la caza y Yucatecuhtli del comercio.

Se han colocado en las puertas los signos de la fecha conmemorativa de la reforma del calendario, que está ligada con las festividades del fuego. Debemos de advertir que alguna de las figuras mitológicas la debemos á la exquisita finura y deferencia del sábio alemán, el profesor Eduardo Seler, quien nos ha facilitado calcas coloridas tomadas del manuscrito original de la Historia de Nueva España, por Sahagún, que existe en Florencia.

Finalmente, para personificar con sus fundamentales acontecimientos la antigua historia mexicana, se han colocado dos grupos; en uno al rey Izcoatl, verdadero fundador de la nacionalidad y de la monarquía, hábil conquistador y prudente político, que sacó á su tribu de la esclavitud para hacerla poderosa; á sus lados se encuentran sus contempóraneos Netzagoalcoyotl, el rey poeta, y Totoquihuatzin, representantes de la triple alianza de México, Texcoco y Tacuba, que tanto poderío llegó á alcanzar en las conquistas de los reyes mexicanos.

En otro grupo se encuentra el heróico cuanto trágico, fin de la monarquía azteca: Cacama Cuitláhuac y Cuauhtémoc, el rey de Texcoco, valiente mártir durante la defensa de México; el segundo, el popular héroe de la Noche Triste el vencedor de Cortés en su retirada por Popotla, y por último, la más grande figura antigua del heroísmo nacional, Cuauhtémoc, el último emperador de México.

Podemos decir en conclusión, que la parte central del edificio representa las ideas capitales de la religión; los pabellones extremos, la agricultura y las artes, elementos principales de su progreso, y las figuras intermedias, el principio y el fin de la antigua civilización mexicana.

Si la comisión ha cumplido con su cometido, si ha conseguido restaurar, en el proyecto que presenta las reliquias más importantes del arte antiguo mexicano, habrá cumplido con un deber de verdadero patriotismo.

México, Mayo 12 de 1888-Antonio Peñafiel. 


\section{PROYECTO DE EDIFICIO PARA EL DEPARTAMENTO MEXIGANO EN LA EXPOSICIÓN DE PARÍS}

Dispuesto de esta manera el edificio, su construcción se hace muy sencilla, pues correspondiéndose las columnas entre sí y con los bastidores que forman los esqueletos de los muros, quedan perfectamente unidos por medio de las trabes, uno y otro de los lados opuestos del edificio.

Sobre el basamento general de piedra se apoyan para formar los muros, unos bastidores de fierro laminado, cuya pieza principal es una doble T de $13 \mathrm{~m} 50$ de largo y de $0 \mathrm{~m} .25 \times 0 \mathrm{~m} .12$ de sección, como puede verse en el cróquis adjunto. Sobre esta pieza vienen á apoyárse en parte, los pisos de las galerías altas y su cubierta. Para dar á los muros la inclinación que afectan en las fachadas, sobre esta doble $\mathrm{T}$ se apoya una $\mathrm{T}$ simple, que siguiendo el talud del muro en el piso bajo, se inclina fuertemente al llegar al segundo cuerpo, y se liga con la doble $T$ por medio de placas remachadas, como se ve en $a$; en el cróquis. Los piés de las dos TT se ligan entre sí por medio de otra T que se asienta sobre el muro de basamento al cual estará unido por medio de tornillos sellados en la piedra. Estos bastidores, situados á $4 \mathrm{~m}$ de distancia, se ligan entre sí por tres cruces de San Andrés, la más alta y la más baja de fierro redondo con sus respectivos templadores, y la intermedia con escuadras de $0 \mathrm{~m} 10$, vueltas del mismo lado, para que sirvan de apoyo á las piezas que sostienen la decoración de las fachadas.

Hay además entre estos bastidores, y en tres puntos de su altura; dobles TT, que á la vez que conservan la distancia respectiva entre ellos, sirven para que se apoyen las TT que sostienen el piso y las cubiertas de las galerías. Estos pisos se formarían de bóvedas $b$ de lámina acanalada y cubierta con betún para poder recibir el mármol que sirve de pavimento. Sobre los bastidores y á cada $0 \mathrm{~m}, 75$ de altura se hallan dispuestas escuadras $c$ de $0 \mathrm{~m}$. 075 de lado; sobre estas se fijarían las piezas $d$, distando entre sí dos metros, que sirven de patrones para la colocación de la decoración de los muros, formada toda de lámina de fierro, dejando unos espacios en forma de cajones $c$, para que una vez terminado el esqueleto general de la construcción, se fije en ellos toda la parte de adornos moldado en zinc y asegurada por medio de tornillos y tuercas sobre estas láminas.

Las columnas de fierro colado tienen 11 metros de altura, $0 \mathrm{~m} .30$ de diámetro en la base de $0 \mathrm{~m}$. 25 en la parte baja del capitel; comprenden los dos pisos, pero están divididas en dos partes para que sea más fácil su construcción; reciben las TT sobre que se apoyan los pisos de las galerías y su cubierta y las trabes armadas que sostienen los tragaluces. Con el fin de que no sean visibles desde el exterior los tragaluces que sirven para iluminari las salas, porque el edificio perdería el carácter que se le ha querido dar, se ha dispuesto una série de pequeños tragaluces transversales, que no alcanzan grande elevación. Estos se apoyan en trabes que van de una á otra columna, cuya forma se ve en el cróquis adjunto, y en el que se nota que en la parte central es mucho más alta que las extremas, teniendo esto el doble objeto de darles una igual resistencia y facilitar el escurrimiento de las aguas que provienen de los tragaluces y que corren por una cubeta colocada sobre la trabe, la cual desemboca en otra de mayores dimensiones que á su vez está en comunicación por medio de unos codos, con 
los tubos de desagüe que se hallan en el interior de las columnas, como se ve en el cróquis bastante detallado para que sea preciso extenderse sobre esto. La cubierta de arriba de las galerías está formada de una semiarmadura que, apoyándose sobre las dobles TT de los bastidores, recibe la lámina acanalada, y las aguas de esta parte se recojen en la misma cubeta que recibe las de los tragaluces.

Lo anterior servirá para dar una idea del sistema que creemos convendría seguirse en la construcción del edificio, sin descender á detallar minuciosamente el resto de ella, por creerlo innecesario.

México, Mayo 26 de 1888.- (Firmado), A. M Anza.

México. Diario Oficial. 7 de junio 1888, p. 1

\section{DOCUMENTO No. 2}

\section{EXPOSICIÓN INTERNACIONAL EN PARÍS}

\section{PROYECTO DE EDIFICIO PARA LA EXPOSICIÓN MEXICANA EN LA INTERNACIONAL DE PARÍS}

"Comisión de ingenieros encargada de la formación del proyecto de edificio para la Exposición Mexicana, en la Internacional de París.

Señor Secretario de Fomento:

Se sirvió vd. designarnos, con acuerdo del C. Presidente de la República, para formar un proyecto del edificio que México deberá levantar para su Exposición en el futuro Certamen Internacional en París

Al comunicársenos nuestro honroso nombramiento, se nos expresó verbalmente el deseo de que el edificio que se proyectase revistiera un carácter especial, que á la vez diera á conocer el grado de cultura de los antiguos pobladores de México.

El pensamiento contenido en ese dato del problema propuesto, merece un elogio, pues significa la iniciativa para creación de un estilo arquitectónico nuevo, que será puramente nacional, puesto que se constituye con los elementos de los monumentos arqueológicos que existen en nuestro territorio.

Dedicados desde luego á nuestro trabajo, hubimos de concretarnos las primeras semanas al estudio de las principales obras que existen sobre arqueología é historia antigua de México, tomando los detalles que pudieran ser conducentes á una composición arquitectónica, de las notables publicaciones de Lord Kinsborough, Waldeck, Chavero, Dupaix y Charnay.

Después de este estudio, la Comisión que suscribe pudo persuadirse de la conveniencia en adoptar para el objeto propuesto un edificio que en sus perfiles y ornamentación caracterizase la arquitectura de las razas más civilizadas de México, pero separándose de las proporciones de los monumentos antiguos que pugnan con las necesidades y gustos modernos. Además, debiendo hacerse 
la construcción con fierro y madera, y en condiciones de poderse desarmar para trasladarse á México, una vez clausurada la Exposición pareció también conveniente, por estas razones, el proyectar un edificio que por su forma y distribución pudiese más tarde utilizarse para un Museo Comercial ó para alguna Oficina importante del Gobierno.

La incertidumbre que hasta el 11 de Abril existió sobre la forma y dimensiones del terreno señalado á México para construir su edificio, no permitió avanzar el desarrollo y ejecución del proyecto, como se habrían podido hacer, pues se temía, y con justicia, que los trabajos hechos fuesen en gran parte infructuosos. Así es que en realidad sólo ha contado la Comisión con algo más de un mes para la ejecución de los dibujos que forman el proyecto que tenemos la honra dé acompañar á vd.

La lámina número 1 representa las proyecciones horizontales de los dos pisos que forman el edificio. La distribución se ha acomodado estrictamente á las dimensiones del rectángulo de 70 metros por 30 metros que tiene el terreno señalado á México.

En el centro del lado mayor de dicho rectángulo, se halla la entrada principal, dando paso á un vestíbulo, á cuya frente está la gran escalera que permite el acceso al piso alto.

La distribución está hecha en vista de las necesidades probables de los grupos diversos en que se dividirán los objetos que se exhiban, y en cuanto ha sido posible se ha fijado para cada grupo la extensión supeficial que habrá menester, así como su colocación más conveniente para el mejor lucimiento de la Exposición. Con unas flechas se indica la marcha que deberán seguir los visitantes, y como se ve en las plantas, es bastante arreglada para evitar toda confusión. Además de los salones, galerías é invernaderos destinados á los nueve grupos que fija el reglamento respectivo para los objetos que se exhiban, se han proyectado salones para la dirección, ó sea para el Delegado de México: para que los Jefes de grupo reciban á las personas que soliciten informes, y para recepción de las personas notables que visiten la Exposición. Por último se han señalado unos cuartos para conserje y servidumbre necesarios para la vigilancia y custodia del edificio.

La lámina número 2 representa un proyecto de fachada hacia el lado menor del rectángulo que forma el terreno destinado al edificio de México.

Los datos que han servido para la composición, son los siguientes: El perfil del basamento esta tomado del templo de Xochimilco: Los almohadillados, grescas y cornisa, de las ruinas de Mitla. El monolito de Tenango se ha usado como pilastras. Como cerramiento de las ventanas de la parte central, se ha colocado un monolito alargado del Sol. En los antepechos de las ventanas se han colocado diversas grecas de la ormentación polícroma que existe en la parte de la obra "México á través de los Siglos," escrita por el Sr. Lic. Alfredo Chavero. Los mascarones de grecas de las ventanas laterales, están derivadas de un barro zapoteca. La parte decorativa de las claraboyas en los terrenos, se tomó en una piedra del sol. Los nichos trapezoidales que se colocaron en los mismos terrenos, y que se destinan para colocar unas estatuas de guerreros ú otras alegóricas, están sacados del cuadro ó margen de un ídolo que trae en su obra el Capitán Dupaix. Y de las piernas de una estatua que hay en la misma obra, la parte decorativa de los entrepaños del segundo cuerpo El cornisa- 
miento general es el del Palacio de Zayi. Las almenas se tomaron del jeroglífico de Tenango, y el coronamiento central, de la figura de un templo esculpida en una piedra que existe en Cuernavaca. Los animales colorados que guardan la entrada del pórtico, son unos ocelotl zapotecas. La fachada descrita se proyectaba como principal para el caso de que la sitnación de terreno obligase á tomar el lado menor del rectángulo como frente del edificio; pero está á la vez adaptada para utilizarse como fachada lateral en el proyecto de distribución adoptado.

En la fachada lateral de la izquierda del edificio (lámina número 3), la composición aunque siguiendo el mismo estilo de la fachada principal, ha variado en los detalles lo mismo que en la ornamentación, por creerse que era conveniente, tanto para evitar la monotonía en el conjunto, como para demostrar la riqueza de la referida ornamentación, al presentar los trazos más notables de lo que constituía la arquitectura de aquellos tiempos. En efecto, para la parte baja ó sea el primer piso, se adoptó para los muros el sistema de almohadillado inclinado que tan común era en los edificios aztecas, copiándolo del cuadro histórico que presenta el descubrimiento del pulque, los basamentos de las ventanas fueron tomados del monumento de Xochicalco y la forma de dichas ventanas, de la puerta subterránea del Palacio del Palenque, que figura en la primera parte de la obra "México á través de los Siglos." Para coronar ó completar los muros y marcar la separación del primer al segundo piso, se tomó por modelo el sistema original de los entablerados que coronaban las paredes del interior de la casa del cura en Mitla, con su variación de bellas é ingeniosas grecas, sistema que según la obra de Lacroix, se vé igualmente adoptado en el exterior del Palacio. En la parte saliente central del mismo pico bajo que debe recibir un mirador ó terraza, sólo se hizo una variación colocando entre los tableros, como mascarones, el sol de la puerta de la casa de "Monjas" que aparece en la citada obra "México á través de los Siglos," alternándolo con el que en la propia obra se ve y que representa el signo omeacatl en la frente de Tonatiuh.

Las medias muestras que se han puesto en los ángulos de la fachada, fueron tomadas originales de las que nos presenta la misma obra como pilastra de los pórticos de Teotihuacán, y en los pedestales que la soportan, se colocó igualmente, como ornato, el que se designa con el nombre de Cruz de Teotihuacán. En el segundo piso la forma de las puertas es la que aparece en el antes citado cuadro histórico del descubrimiento del pulque, y para rematarlas pareció muy propio colocarles como capelos la parte superior del solio que se ve en el mismo cuadro. En la ornamentación de este segundo piso figuran alternados y en grandes tableros, los mejores mascarones del Palacio de "Las Monjas;" sobre unos semicilindros de los que contienen las secciones del Palacio de Zayí, llevando en la faja superior unas estrellas de la tarde.

Las medias, muestras de los ángulos se formaron tomando de la repetida publicación las dos secciones que en su conjunto representan los soles mahoas ó edades del agua, del aire, del fuego y de la tierra, y están, designados con el nombre de "Monolito de Tenango." En el friso, entre los balcones, se colocó como ornato una alegoría del Sol, y en los tableros de los mismos balcones, el dios del viento, ó sea Quetzalcoalt. El cornisamento que corona el edificio, está 
formado, siguiendo el estilo, de molduras que en general aparecen en los monumentos antiguos mexicanos, y ornamentados con grecas del Palacio de Mitla y semicilindros del de Zayí; y por remate lleva un almenado en la disposición y forma que aparece en el cuadro histórico del juego de pelota del $\mathrm{Sr}_{\text {. }}$ Ibarrarán. Figura en el centro un remate en cuya composición entraron una esfinge que se haya en lá obra "México á través de lọs Siglos," una culebra con cabeza tomada de una de las del Palacio del Gobernador, y el Sol de la piedra de Cuautitlán.

El balaustrado del mirador contiene unos tableros que llevan en semicilindros el que aparece como comentario de la Corrección, y en el frente el símbolo de la Luna, su sueño y su desvelo, cerrando como balaustres los que se ven como una sección de la puerta de Kewick. La lámina número 4 representa la sección según el eje del vestibulo. En la decoración de la planta baja figuran originales las columnas y capiteles toltecas que aparecen en la obra del Sr. Chavero; unos tableros con escudos de armas aztecas,sobre unos frisos en que figuran grecas y pequeñas secciones cilíndricas de una colección especial que el Sr. Alva formó, tomada de la obra de Lacroix. En la parte superior están alternados unos tableros en la forma de los que existían en el interior de la casa del cura en Mitla, unas estrellas de la tarde, unas grecas y una sección de semicilindros del Palacio Zayí. En el cubo de la escalera figura, sobre la segunda meseta, la rueda de los años, que también existe en la obra del Sr. Chavero; debiéndose advertir, que en la decoración de las demás paredes del mismo cubo, se ha llevado la idea de colocar simétricamente las otras tres ruedas que, con la de que se acaba de hablar, forman las cuatro que representan las diversas divisiones del tiempo en dias, meses, años, etc. Figurará también, sobre la última meseta, la gran rueda que existe y se designa con el nombre de Calendario Azteca " La gran entrada á las galerías de la Exposición, está, según se ve formada por un arco ó puerta que original se tomó de la muestra de los corredores del Palacio de Nachan (Palenque) La descripción de esta forma de arco está en la página 212 de la obra "México á traves de los siglos," y dice: "No es triangular sino que comienza con la ojiva, y antes de cerrarse se abre de nuevo y al fin se cierra ojivalmente." El arco tiene la forma de hoja de trebol, y recuerda las construcciones arábigas.

En la parte del piso superior, y todavía en el cubo de la escalera, el decorado lo forman: Un friso de grandes grecas, luego un gran tablero con un mascarón de la casa de "Las Monjas" y en seguida rematando unas grecas tomadas de los muros de Kabah, de la publicación que se acaba de citar. Las puertas de comunicación conservan el mismo estilo que las de la fachada lateral que se ha descrito, con ligeras variaciones en su coronamiento, pero siempre siguiendo el estilo. En la sala de recepción figuran unas columnas lisas, sin bases y con capiteles en los que se ha procurado seguir el estilo azteca. En el friso figuran unas grecas de las que posee el Sr. Alva en una colección; después una faja de semicírculos concéntricos, siguiendo una faja de los semicilindros ya conocidos. A continuación se ven unos grandes tableros con el Sol y cabezas de serpientes, también de los datos del Sr. Alva, pero que se hayan igualmente en la casa de "Las Monjas" en Uxmal; y por último, otra sección de semicilindros, perteneciente á los mismos tableros, con estrellas de la tarde. Las puertas que del salón de recepción conducen á las galerías, conservan la misma forma adop- 
tada, llevando como remate unas grandes grecas, y en el centro un bajo-relieve que representa el busto de una sacerdotisa azteca, copiada de la obra del $\mathrm{Sr}$. Chavero.

La lámina número 5 corresponde á la fachada principal ó sea al lado de 70 metros del rectácgulo que afecta el terreno en su forma. La altura comprendida entre el piso y la tangente superior del ornato colocado como coronamiento en la parte central, es de 17 metros 20 centímetros, subdividida en $\mathbf{5}$ metros 80 centímetros para el piso bajo, 6 metros para el segundo piso hasta la cornisa, $y$ el resto para coronamiento.

En la parte central se pusieron tres grandes claros para la entrada al edificio, perfilados según se halla el puente de Nachan, en Palenque. Entre estos claros se colocó una especie de almohadillado de placas sobrepuestas, calcado de la pirámide de Papantla, y encima de este almohadillado, un pequeño cornisamento ornamentado con una greca de paletas, sacado de la obra de Lord Kinsborough para determinar la separación de un tablero sencillo en cuyo centro se pusieron unas cabezas de tigre tomadas de la figura en barro que existe en nuestro Museo Nacional A los lados de esta parte central que se halla en relieve respecto al paño general del edificio, y que corresponde al pórtico, se desprenden las porciones laterales de fachada que corresponden á las galerías de los grupos $5^{\circ}$ y $9^{\circ}$. Las ventanas, en su basamento, afectan el perfil de ornamentación del monumento que existe en Xochicalco y ha sido tomada de la obra "México á través de los Siglos." El cerramiento de las mismas ventanas pertenece al monumento llamado "Las monjas," que se encuentra en Chinchen Itza, y fué copiado de una ilustración de la obra escrita por el $\mathrm{Sr}$ Charnay. En los entrepaños de las ventanas se formaron unos tableros llenos con la rica ornamentación del templo de Itzalá que describe y representa en su interesante publicación el Sr. Waldeck, titulada: "Viaje Arqueológico y Pintoresco en Yucatán;" sobre esta sección se puso el Nao-ollin de la obra de Kinsborough. El cornisamento que divide el primero del segundo piso, es una composición basada en los perfiles característicos de la arquitectura maya, con una ornamentación de cilindros yuxtapuestos, tomada del Palacio de Zayí. La parte central del piso superior consta de tres ventanas con grandes grecas como antepechos, y una trenza como chambranas, tomadas de la obra de Waldeck ya citada El perfil de estas ventanas se calcó de una puerta que se halla en las ilustraciones de la publicación del Capitán Dupaix y que se relacionan con los monumentos del Palenque En los entrepaños de las ventanas se puso una greca de conchas, tomada de la ornamentación policroma que hay en la otra del llavero; encima se ve, encerrada en un tablero, la figura alegórica de la reforma del calendario azteca, y hasta el nivel del cerramiento, una sección de grecas que recuerdan el Palacio de Mitla ornamentado con grecas tomadas de las repetidas obras de Waldeck y Chavero Como remates en el cerramiento de las mismas ventanas, se puso un mascarón que existe en el monumento de Itzalá, y á nivel de ellos se colocaron bajo-relieves de Tonaca. tecutli. Los tramos laterales de fachada guardan en sus ventanas una forma análoga á los de la parte central; pero se hallan sin antepechos de grecas ni chambranas, rematando el cerramiento un almenado sobre el que resalta una cabeza tomada de un vaso cinerario de Tlacolula, y que forman parte de las ilustraciones de la obra del $\mathrm{Sr}$. Chavero. En los entrepaños se colocaron unos 
tableros llenos, con una gran greca que existe en Itzalá, según Waldeck expresa en su libro sobre Yucatán. El mismo órden de grecas que en la parte central, se halla hasta el nivel de los cerramientos, acortándose los entrepaños con un bajo-relieve sacado de un mascarón de la casa del Gobernador en Uxmal, y que se tomó de la publicación "México á través de los Siglos."

La cornisa del segundo piso se ha inspirado en las ruinas de Mitla, para el perfil general; y se ha ornamentado sencillamente con unos cilindros horizontales en la parte central, y con una trenza ó petatillo, sacado todo esto de la obra de Lord Kinsborough. Sobre la cornisa se puso un pequeño zócalo con almenado, y en la parte central el remate ó coronamiento formado por una caja con greca, unas trompas invertidas y un tablero remendado un templo que lateralmente tiene unas cabezas de serpiente y en su parte superior un cornisamiento con su remate, tomado de una fotografia que hay en el Museo Nacional. A excepción de este detalle, el resto del coronamiento se ha formado con elementos sacados de la obra de Waldeck sobre Yucatán. Dentro del tablero expresado se colocaron las armas nacionales.

Ha entrado la Comisión á detallar las diferentes partes que constituyen el proyecto de edificio que acompaña á este informe, con el objeto de comprobar la exactitud de los elementos de que está formado y dar, como es debido, á cada autor de las obras que se han consultado, el mérito que les corresponde. La Comisión protesta á vd., señor Ministro, haber procedido con todo empeño en el laborioso trabajo que tuvo vd. la bondad de encomendarle, y desea que el proyecto de edificio que presenta como resultado de sus estudios, sirva, por lo ménos, para cooperar al pensamiento de crear un estilo arquitectónico nacional. -Sr. Luis Salazar.-V. Reyes - Jose M. Alva

México El Municipio Libre, 18 de junio de 1888, p. 1-2.

\section{DOCUMENTO No. 3}

\section{CARTAS DE PARÍS}

[Por Cable á la Press Publishing Company, de N. York]

$$
\text { -Traducido para el "Siglo XIX"- }
$$

París; Julio $1^{\circ}$ de 1889.

Una inmensa concurrencia llenaba hoy la Galería de Pinturas de Sedelmeyer, para presenciar la venta de la famosa colección Secretan. La atmósfera era casi tropical, y sin embargo, nadie se ausentaba, esperando el resultado; y, como se había dicho que los fondos del Departamento de Bellas Artes no serían bastantes para hacer frente á las pujas, sobre todo, tratándose del "Angelus," de Millet, todos esperaban ver aparecer algun millonario americano, dispuesto á llevárselo, á cualquier precio. 
Comenzó la venta por las acuarelas; y "Los Jugadores de Ajedrez," de Meissonier, alcanzaron la cifra de 22,500 francos.

Llegó á hacerse intensa la excitación del público, cuando el veadutero pasó á las pinturas al óleo. Los precios alcanzados sobrepujaron á cuanto se había esperado. Los principales fueron: "Sur la Plage," 20,000 francos; "Le Matin," de Corot, 36,000 francos. Cuando tocó su turno al "Angelus", de Millet, la excitación llegó á su máximun. Cuando la puja llegó á 400,000 francos, la lucha quedó circunscrita á $\mathbf{M}$. Proust, representante de la Galería Corcoran, y á $\mathbf{M}$. Avery, de New York. Siguió la puja. Finalmente, el representante francés llegó á 554,000 francos, en cuyo precio fincó el remate. Cuando se supo que el cuadro se quedaba en Francia, hubo prolongados aplausos.

"Los Perros," de Decamp — un bulldog y un ratonero escocés-llegó á 25,000 francos; y otro cuadro, del mismo maestro, alcanzó la suma de 70,000 francos. "Le Frondeur" se vendió en 92,000 francos.

El total de esta primera venta llegó á .... $3.700,000$ francos $(\$ 740,000)$

Julio 2.

La venta de las pinturas de la colección Secretan continuó hoy. El núm. 120, "Interior de una Casa Holandesa," por Hooge, fué comprado por Durandkuel, en $\$ 55,200$. El núm. 158, "Abigail yendo al encuentro de David," por Rubens, lo remató en $\$ 22,000$. Scrips. M Agnew compró los siguientes cuadros: Núm. 123, "Retrato de Pieter Van der Broeke," por Hals, en $\$ 22,000$; núm, 143, "Almuerzo", por Metzu, en $\$ 19,000$; núm. 142, "Interior holandés," por Metzu en \$12,000; núm 130, "La Ama y la Criada," por Van der Meer, en ..., \$15,000.

El núm. 140, "Le Billet-doux," por Van der Meer, se vendió en $\$ 12,400$, y el núm. 114, "Retrato de Ana Cavendish, Lady Riche," por Van Dyck, alcanzó el precio de $\$ 14,800$.

"Los Cinco Sentidos: Vista, Oido, Gusto Tacto y Olfato," en $\quad \$ 12,030$.

Otras ventas, fueron como sigue:

Núm. 104 Una vista de Venecia, Canal

Núm 107. Artista copiando de la naturaleza, de Cuyp ......... $\quad 8,200$

Núm. 111. Retrato de la Condesa Dubarry, de Drouais ....... $\quad 7,300$

Núm. 117. La Familia feliz, de Fragonard ............................... $\quad 9,000$

Núm. 127. Interior holandés, de Hals ................................. . $\quad 6,100$

Núm. 131. Familia holandesa en un aposento de Keyser ...... $\quad 4,900$

Núm. 133. Placeres del Invierno, de Langret ............................... $\quad \mathbf{6 , 8 0 0}$

Núm. 138. Retrato de Stephen Gardiner, Obispo de Win-
chester, y Gran Canciller de Inglaterra, de Mateyos .................

Núm. 149. El Juego interrumpido, de Ostade ...................... $\quad 5,300$

Núm. 152. Hombre con armadura, de Rembrandt ................. $\quad 4,600$

Núm. 154. Retrato de la hermana de Rembrandt ........................ $\quad 5,900$

Núm 146. La Viuda y su hijo, de Reynolds ................................. $\quad 5,400$

Núm 160. La Compuerta, de Ruysdael .................................... $\quad 7,400$

Núm. 162. La Encajera, de Slingelandt ................................ $\quad 5,300$

Núm. 170. El Pozo, de Teniers ...................................................... $\quad 4,300$ 
Cristina Nilsson, Condesa de Miranda, compró el "Retrato de la Condesa Dubarry" de Drouais, en $\$ 7,300$.

La venta de hoy subió a $\$ 381,000$.

Mr. Sutton, el coleccionador americano, ha ofrecido regalar á los pobres de París la suma de 50,000 francos, si M. Proust quiere cederle el "Angelus" en el precio que pagó por este cuadro, es decir, por 554,000 francos.

México. El Siglo Diez y Nueve. 13 de julio de 1889 . p. 2.

DOCUMENTO No. 4

\section{EL PABELLÓN MEXICANO \\ EN LA \\ EXPOSICIÓN DE PARÍS}

Un periódico de hoy traduce de Le Matin las siguientes líneas que se refieren á la reciente inauguración del Pabellón de México en la Exposición Universal de París:

"Decididamente, el Sr. Carnot es infatigable. El viernes inauguraba la Exposición colonial en la explanada de los Inválidos. Ayer, en la noche, se transportaba al Campo de Marte, y teníamos una nueva inauguración: la de la Exposición mexicana, reforzada con una encantadora fiesta nocturna.

A las nueve, el Presidente de la República llegó al Campo de Marte por el puente de Iéna, en compañía de la Sra. Carnot y del Sr., Tirard, presidente del Consejo.

La multitud, muy numerosa, lo aclamó inmediatamente. Sin embargo, debemos decir que algunos aplastados tomaron a mal que se les impidiese ver á sus anchas el Juego de las fuentes luminosas.

Muy bueno el servicio para conservar el órden, admirablemente organizado por los Sres. Montpellier y Thiẻbaud, oficiales de paz. Dichos señores tomaron su revancha de la barahunda del viérnes, que erróneamente se les ha echado en cara.

El pabellon mexicano, hermosa y grande construcción de estilo exótico, estaba alumbrando por dos grandes tripodes en los que ardian fuegos rojos del más bonito efecto. La exposición, propiamente dicha, resplandecía de luces.

El Sr. Carnot, acompañado de su séquito, fué recibido en lo alto de la escalera por los Sres. Alphand y Berger, el señor senador Ramon Fernández, ministro plenipotenciario de México, el Sr. Gustavo Baz, primer secretario de la legación, las notabilidades de la colonia mexicana y la comisión. Inmediatamente, excelente música del 101 de línea, formada delante del pabellon, tocó la Marsellesa.

En ese mismo instante, la torre Eiffel se vió cubierta de fuegos de bengala, y las fuentes luminosas se pusieron en juego, para mayor placer del público.

Digamos también que, conforme al programa, los palacios de Bellas Artes y de Artes Liberales, fueron magníficamente iluminados. 


\title{
LA INAUGURACIÓN
}

Despues de una corta alocución del comisario general de la Exposición mexicana, el señor y la Sra. Carnot, siempre acompañados del presidente del Consejo, recorrieron el interior del pabellon, interesándose muchísimo en esta exposición encantadora.

El golpe de vista era muy agradable. En torno del presidente se agrupaban enjambres de mujeres bonitas que pertenecian á las colonias mexicanas y sub-americanas. Los preciosos vestidos claros hacian pintoresco contraste con los negros trajes de los personajes oficiales. Durante la visita presidencial, una música mexicana tocó diferentes trozos, que alternaban con las conversaciones del presidente y la comisión.

Los aires nacionales mexicanos fueron muy aplaudidos por el Sr. Carnot.

Hé aquí el programa de los demás trozos ejecutados:

México, marcha solemne.

El Cocoyer, berceuse tropical.

Saludo á Francia, himno triunfal.

Melancolía, aire de danza.

Obertura de la Muda.

Habanera.

Juntitos, danza.

Trozos escogidos de Romeo y Julieta.

Todas las piezas exóticas de ese programa se deben á los excelentes compositores mexicanos Eugenio Michel y Navarro.

El Sr. Carnot, despues de haber pasado revista á todos los productos expuestos, se dirigió á pié hácia el pabellon del Gas, donde permaneció bastante tiempo. El presidente del consejo daba el brazo á la Sra. Carnot.

México. El Siglo Diez y Nueve. 17 de julio de 1889, p. 1-2

\section{DOCUMENTO No. 5}

\author{
INAUGURACIÓN \\ DEL \\ PALACIO MEXICANO \\ EN EL CAMPO DE MARTE
}

De un periódico parisiense traducimos lo que signe:

"Como lo habiamos anunciado, el sábado último se verificó la inauguración oficial del soberbio palacio que el gobierno de México ha hecho levantar en el Campo de Marte, para que en él fueran expuestos los productos tan variados como ricos de la industria y del suelo mexicano.

Pero ántes de dar cuenta de esta fiesta brillantísima, nos creemos obligados á presentar algunos detalles relativos al edificio que admitan todos cuantos visitan la Exposición Universal.

No hay, según tenemos entendido, en todo el Campo de Marte, ninguna 
construcción que sea más curiosa, bajo el punto de vista arqueológico, que la que se debe á la ciencia y al talento de los Sres. Peñafiel y Anza.

El Palacio Mexicano, de planta rectangular, mide 70 metros de extensión longitudinal y 30 metros de anchura, por 14 metros 50 centímetros de altu$\mathrm{ra}$, contando dos pisos. La fachada comprende una sección general avanzada, en conexión con los pabellones extremos,menos salientes, por medio de una parte que reentra.

Los tres costados restantes se encuentran en un mismo plan y están decorados con grecas de tanto mayor mérito, cuanto que las curvas no figuran ahí en lo absoluto, haciendo excepciones, sin embargo, del friso que corona el palacio; á pesar de esta particularidad, son muchas las combinaciones, y los motivos no carecen de amplitud ni de elegancia.

Un muro del antiguo palacio de Huexotla, perfectamente conservado y conocido con el nombre de Texolocalco, así como el magnifico monumento de Xochicalco, en el Estado de Morelos, y los restos de otros monumentos encontrados en virtud de las investigaciones del Dr. Peñafiel, han permitido al sábio arqueólogo mexicano la formación del proyecto de un palacio azteca, que le fué pedido por su gobierno, para la Exposición de 1889.

La parte más interesante de la notable reconstrucción, es la fachada que, con tal motivo, merece una descripción especial

La parte central simboliza la religion azteca; en la parte média del edificio se nota una ancha escalera casi á pico, de muy elevados peldaños, que recuerda las de los antiguos teocallis; dicha escalera dá acceso al piso superior mediante una ancha pero poco elevada abertura que dos cariátides dividen en tres salidas. El original de esas cariátides, que sustentan el friso del fróntis, fué encontrado por el Dr. Peñafiel en las excavaciones practicadas en Tula, antiguo centro de la civilización tolteca, y es el único soporte completo que existe hasta hoy; representa á un hombre que tiene cubierta la cabeza con un casco formado por la cabeza de una serpiente cuyo cuerpo constituye la cauda; está vestido con paño ó maxtli y tiene un escudo sobre el pecho, signo distintivo de los grandes personajes. Los costados de la escalera, adornados con el signo del fuego, van coronados por los braseros de Huehueteotl en los cuales se encendia periódicamente el fuego nuevo, el fuego secular, gran acontecimiento religioso entre los pueblos del Anáhuac

Por encima de estos detalles de cierto carácter muy bello, corre la greca del friso dando vuelta á todo el palacio; dicho friso se ve rematado con una cornisa copiada de la que se encontró en las ruinas de Xochicalco

El sol, divinidad que adoraban bajo el nombre de Tonatiuth, remata el pórtico: está rodeado de sus atributos y preside la creación del Cipactli que representa la fuerza fertilizante de la tierra

Ásí, pues, esta parte del palacio indica los dos grandes cultos de los Aztecas; Huehueteotl, el fuego, y Tonatiuth, el sol, los cuales, segun el Dr. Peñafiel, acabaron por identificarse y no formaron sino un solo culto.

Terminaremos esta descripcion indicando que los tres personajes que figuran sobre cada uno de los pabellones laterales, por encima de mas puertas de entrada que dan acceso al departamento bajo el edificio son Tlaloc, dios de las aguas; Centeotl, divinidad con dos rostros, uno de los cuales corresponde á las cosechas abundantes y el otro á la escasez; Chalchiutlicue, diosa dispensadora de 


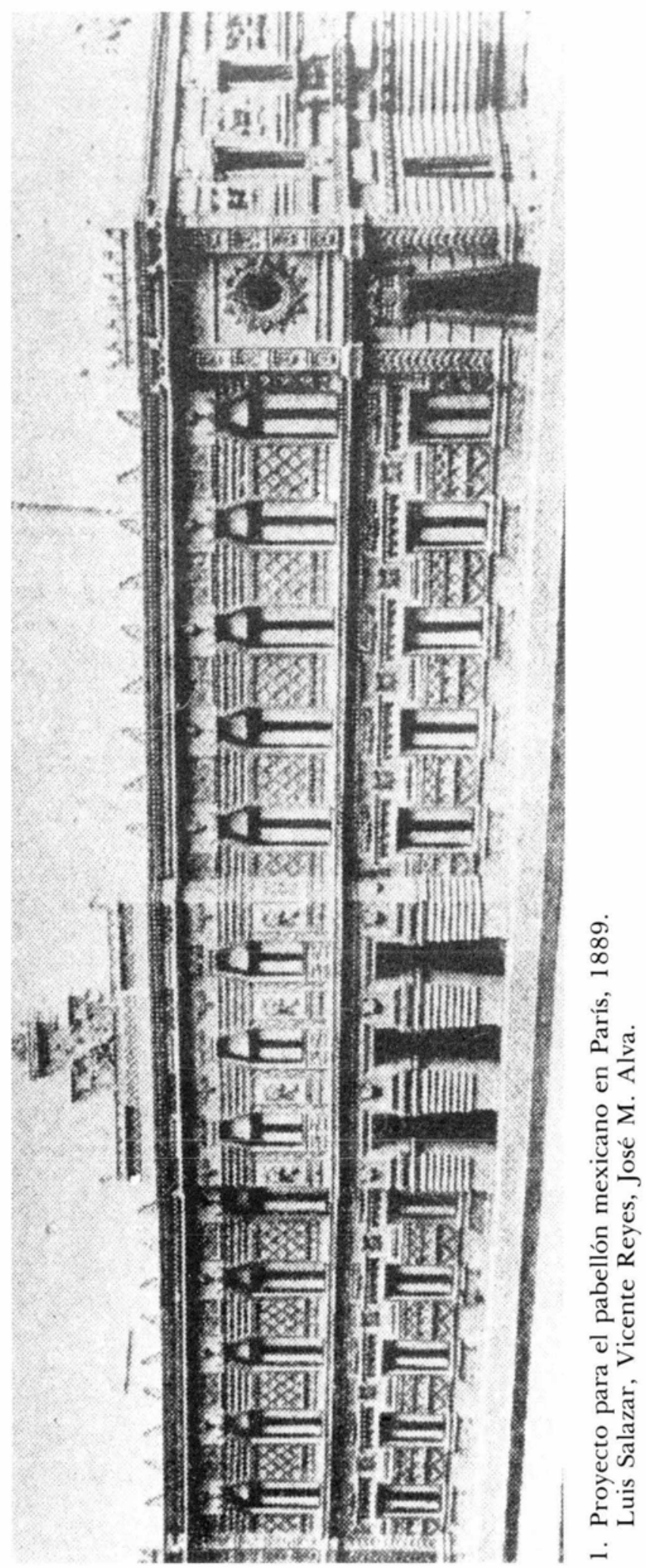


DOI: http://dx.doi.org/10.22201/iie.18703062e.1990.61.1576

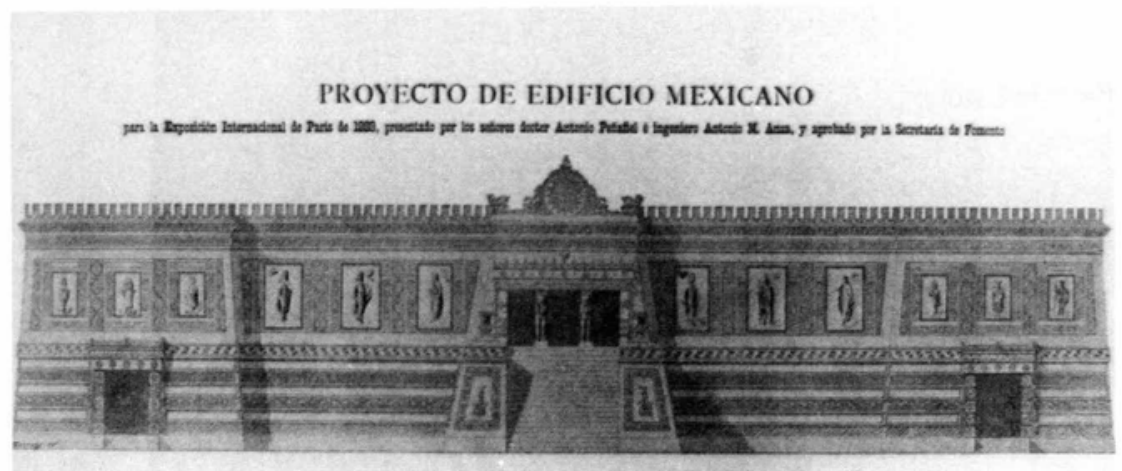

2. Proyecto de edificio mexicano en París, 1889.

Antonio Peñafiel y Antonio M. Anza.

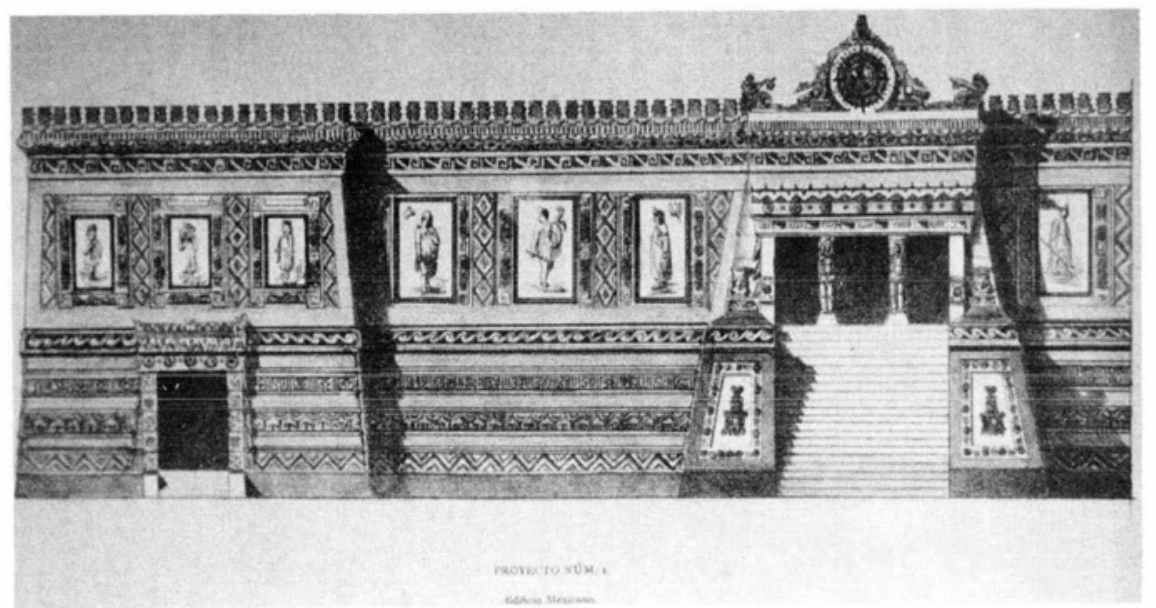

3. Proyecto de edificio mexicano en París, 1889. Detalle. Antonio Peñafiel y Antonio M. Anza. 
DOI: http://dx.doi.org/10.22201/iie.18703062e.1990.61.1576

4. Pabellón mexicano. Planta alta y planta baja.

Antonio Peñafiel y Antonio M. Anza.
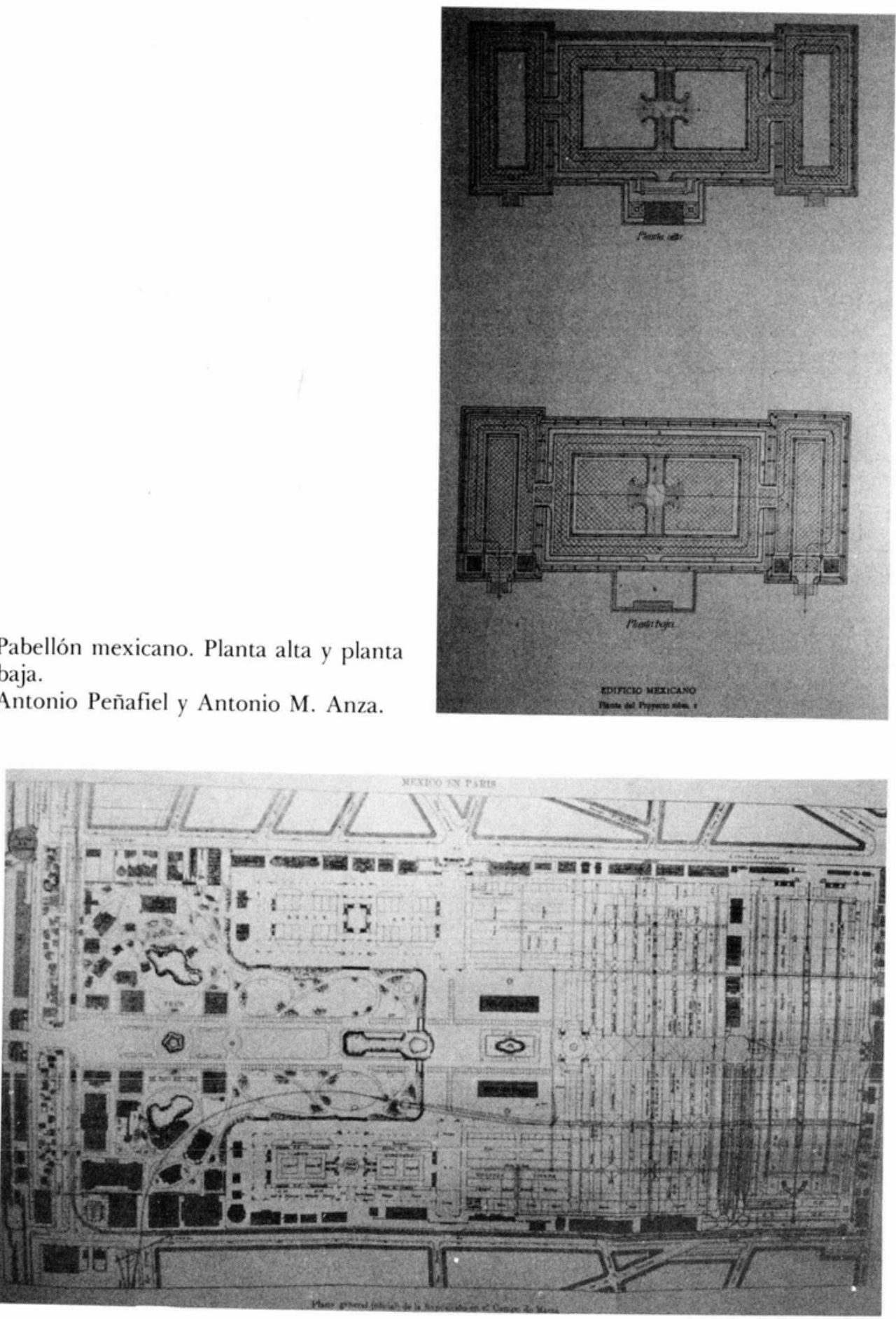

5. Plano general de la Exposición Universal en el Campo de Marte. París, 1889. 


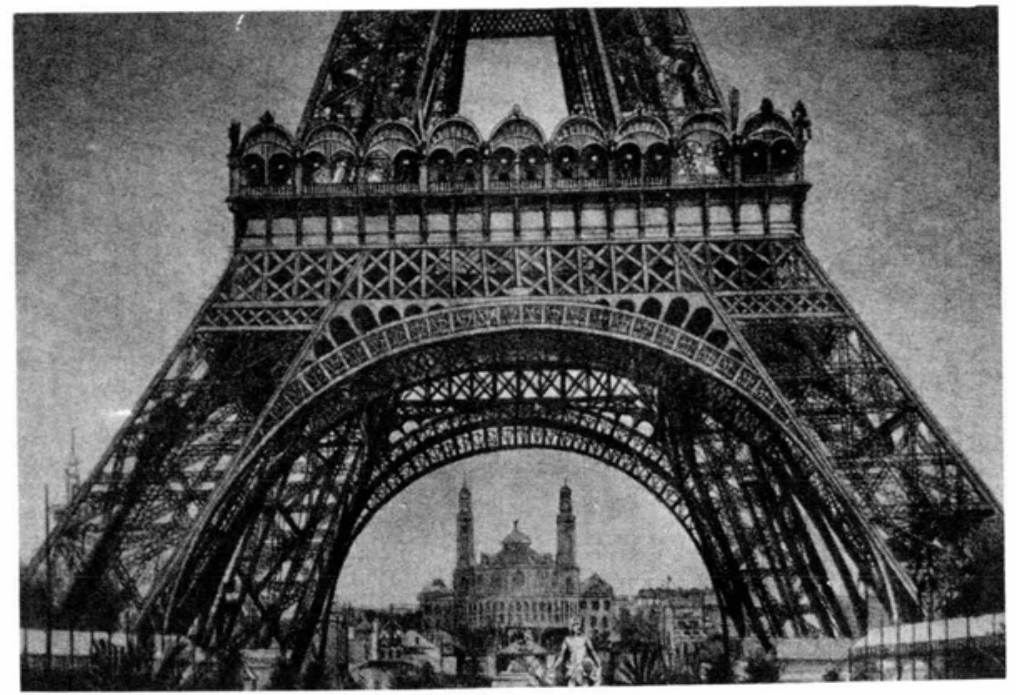

6. Base de la Torre Eiffel con el Trocadero al fondo. París, 1889. Litografía de Hesiquio Iriarte.

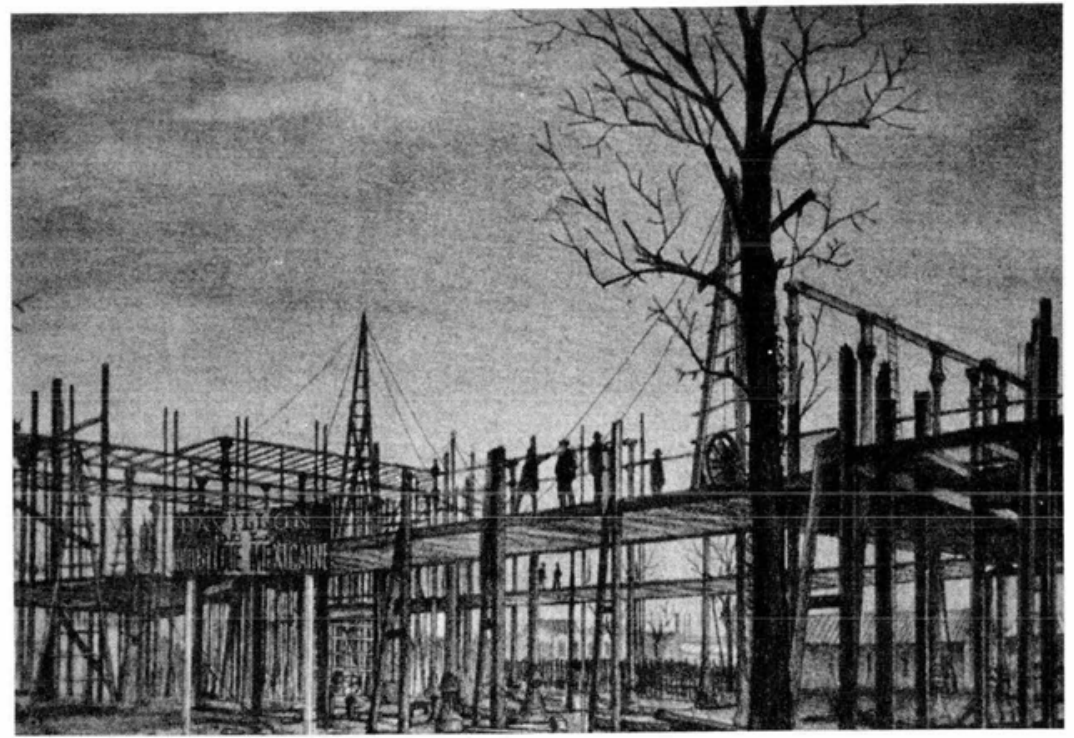

7. Edificio mexicano, fotografiado el 18 de febrero de 1889. 


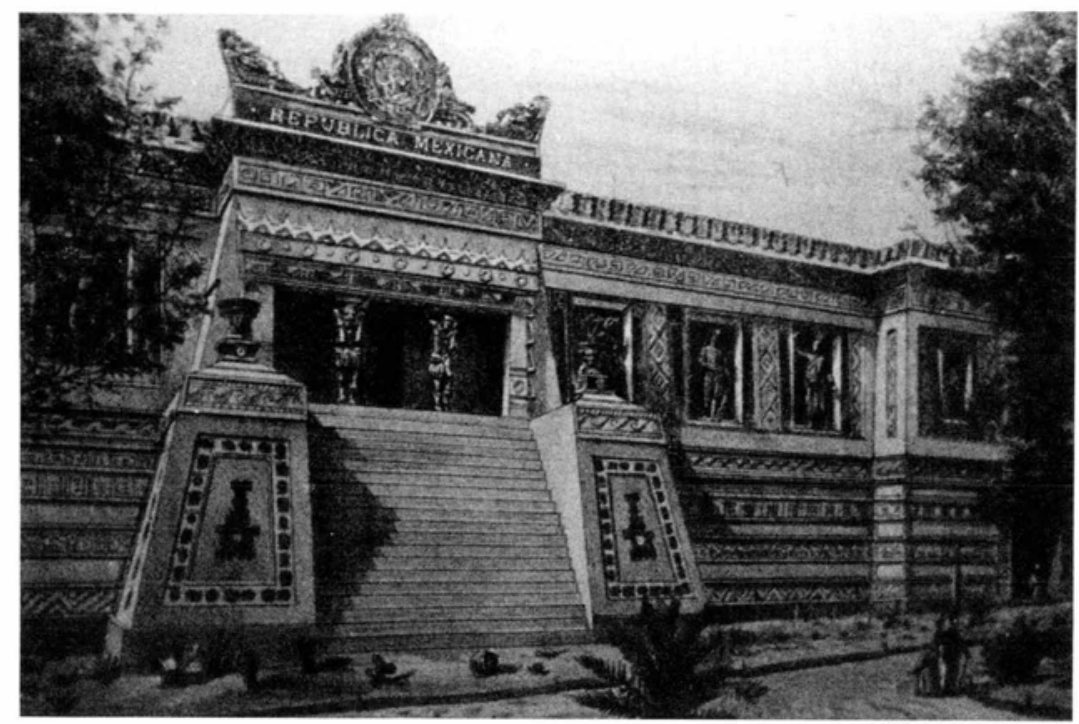

8. Fachada del pabellón mexicano.

Litografía de Hesiquio Iriarte.

9. Entrada al pabellón mexicano. Litografía de Hesiquio Iriarte.

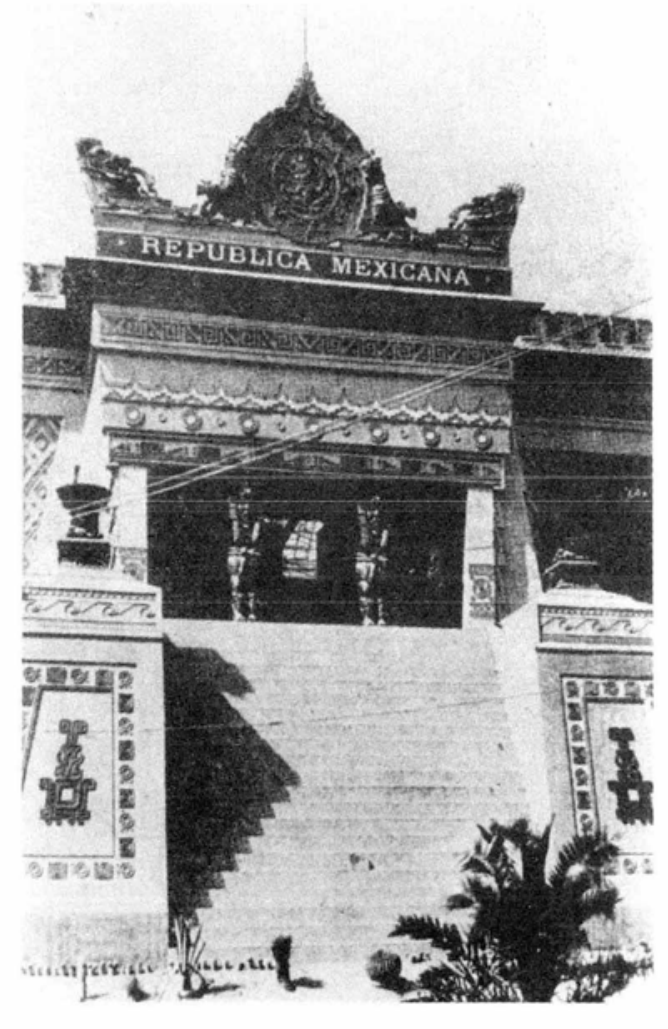


DOI: http://dx.doi.org/10.22201/iie.18703062e.1990.61.1576

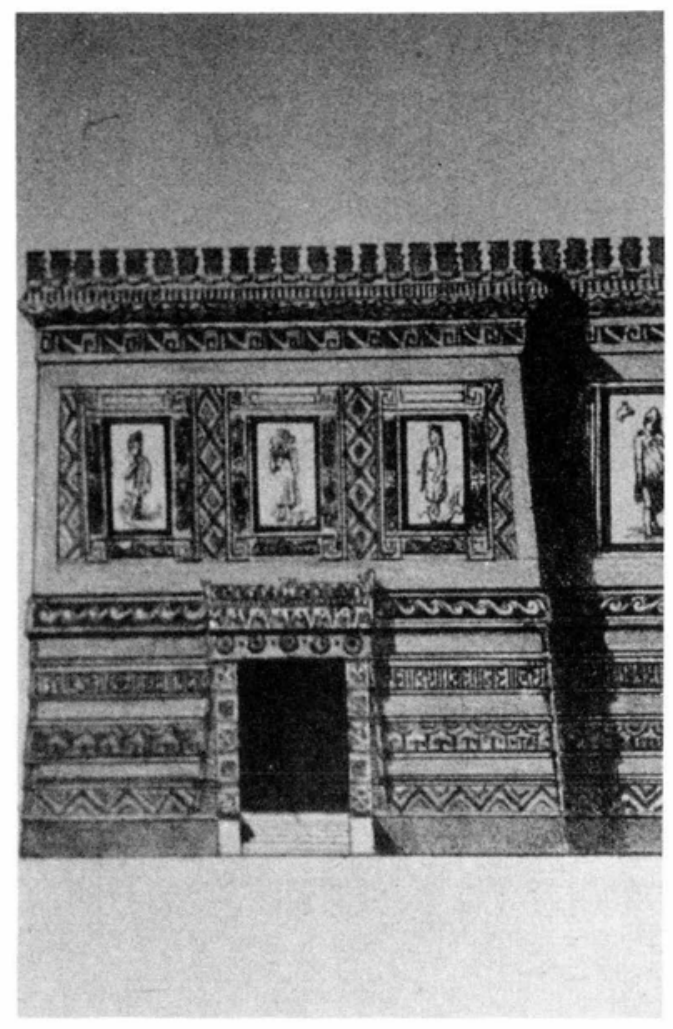

10. Pabellón mexicano.

Detalle del lado izquierdo.

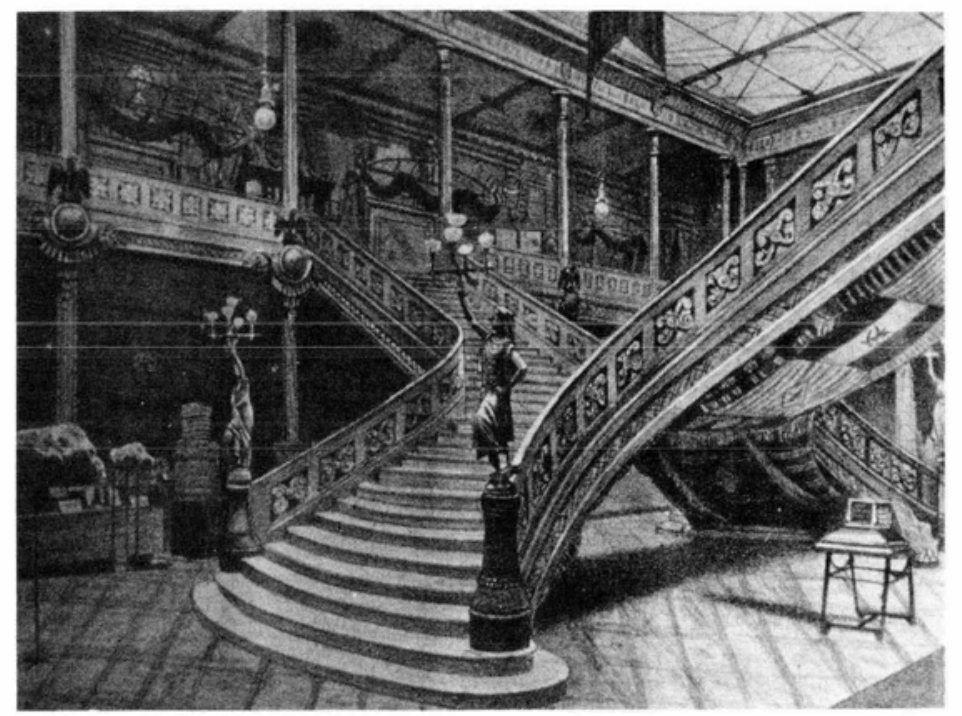

11. Interior del pabellón mexicano: escalera principal. (Portafaro de Jesús Contreras.) 
los beneficios del agua; Xochiquetzali, diosa de las artes; Camaxtli, diosa de la caza y Yacatecuhtli, dios del comercio.

Los seis personajes que pertenecen á las historias son: Itzcoatl, fundador de la autonomía mexicana; Netzahualcoyotl, el rey poeta, una de las más nobles figuras de la antigüedad azteca; Totoquihuatzin, primer aliado de la monarquía de Tlacopan, con los mexicanos; Cuitlauhuac, Cacamatzin, y finalmente Cuauhtemoc, el rey mártir y el último de los monarcas mexicanos.

El interior del palacio no es ménos grandioso y corresponde á la riqueza arqueológica del exterior. Dividido en tres partes, una gran sala central y dos compartimientos laterales de grandes proporciones, ofrece un aspecto de lo más imponente; una de las cosas que más sorprenden es la escalera que conduce á las galerías del piso alto.

Esta escalera, cuya disposicion, tan atrevida como original, honra á su autor el ingeniero Anza, maravilla por su ligereza y por su aspecto monumental.

En nuestro próximo número nos ocuparemos más en detalle de la decoración de las salas y galerías.

La inauguración oficial del Palacio mexicano se verificó a las nueve de la noche. Innumerables torrentes de luz eléctrica inundaban la fachada y ponian de relieve las líneas majestuosas y los detalles tan originales de la rara construcción. Una muchedumbre compacta estacionada en las cercanías del edificio, manifestando en alta voz su admiración por la idea reconstructora de una arquitectura olvidada y desconocida ya.

El interior presentaba un golpe de vista realmente feérico; globos incandescentes, distribuidos con profusión, aumentaban el brillo deslumbrador de los ricos minerales, la transparencia de los onyx, la coloración de los tejidos atigrados y los matices de las maderas preciosas de esta exposición, una de las más bellas $\mathrm{y}$, sin duda, la más completa de todas las que figuran en el Campo de Marte.

A las nueve y media de la noche un cañonazo disparado desde la torre Eiffel indicó que el Jefe del Estado penetraba á la instalación de México. En el dintel del Palacio, el Sr. Ramon Férnandez, de gran uniforme y rodeado por el personal de la Legación mexicana, el Sr. Diaz Mimiaga, comisionado general y los miembros del Comité, esperaban al, Presidente de la República y á Mme. Carnot.

El arribo del Primer Magistrado fué saludado con la "Marsellesa" y con el Himno Nacional Mexicano,"admirablemente instrumentado por D Alfredo Bablot, director del Conservatorio de Música de México y Secretario general del Comité.

La visita del edificio se comenzó desde luego bajo la dirección del Sr. Diaz Mimiaga, quien suministraba á Mr. Carnot todas las explicaciones que éste le pedia sin cesar.

La Sra. de Diaz Mimiaga, aunque todavía no completamente aliviada, recibió á la esposa del Presidente francés, y con gracia encantadora, asociada á una exquisita distinción, hizo los honores á Mme. Carnot en el Palacio de México.

La presidenta, tanto como su ilustre consorte, felicitaron calurosamente á los organizadores de la instalación mexicana y no disimularon la agradable sorpresa que les causó, no solamente la profusión de las riquezas del suelo de México, sino tambien los grandes progresos realizados por la industria nacional, y por 
el grado elevado que así las ciencias como las letras han alcanzado en la República.

Miéntras duró la visita presidencial, una excelente orquesta ejecutó diversas composiciones de autores mexicanos y varios aires nacionales, que fueron muy aplaudidos.

Antes de que abandonase el Presidente el Palacio Mexicano, encamináronse los circunstantes á un salon reservado, donde se había tenido cuidado de instalar un buffet abundante y régiamente servido.

El Presidente de Francia apuró una copa de Champagne á la salud del Presidente de México, el ilustre general D. Porfirio Diaz y á la prosperidad de la República Mexicana.

En aquellos momentos la señora de Diaz Mimiaga ofreció á Mme. Carnot un magnifico bouquet de flores muy raras, atadas entre sí con un liston formado con los colores mexicanos.

La salida del Presidente Carnot fué saludada con los acordes de la Marsellesa y con los del Himno Nacional Mexicano.

Toda la colonia mexicana y las familias más distinguidas de la América Española, residentes en París, se apresuraron á responder á la invitación que el amable Comisario general les dirigió, y no era, en verdad, el espectáculo ménos atractivo, el que ofrecia aquella multitud de jóvenes bellas y elegantes, que constituyen el orgullo del Nuevo Mundo.

No terminaremos esta crónica sin enviar nuestras más sinceras felicitaciones á los iniciadores y organizadores de tan soberbia Exposición.

El honor y la gloria del éxito refluyen, en primer lugar, sobre el presidente de México y sobre el general Pacheco, Ministro de Fomento, el que -fuerte con el apoyo absoluto que le otorgó el Jefe del Estado,- realizó verdaderos prodigios y permitió que el mundo entero pudiese apreciar, como es debido, las riquezas de todo género que con la naturaleza dotó á esa tierra mexicana cuyo porvenir es tan grande.

Una gran parte del éxito obtenido se debe al comisario general D. Manuel Diaz Mimiaga y á los demás miembros del Comité, sus inteligentes colaboradores. Aquí la opinion pública les ha hecho justicia y ha aplaudido el triunfo de sus perseverantes esfuerzos.

México, á su vez, no dejará de manifestarles su reconocimiento por su conducta tan patriótica.

México, El Siglo Diez y Nueve. 20 de julio de 1889 ; p. $1-2$

DOCUMENTO No. 6

\section{LA EXPOSICIÓN DE PARÍS \\ LA PINTURA AUSTRIACA HÚ NGARA Y LA ALEMANA}

Apenas enträis en la sección de Austria Hungría del Palacio de Bellas Artes, veis á vuestra derecha un vasto lienzo cuyo movimiento y cuya composición dramática os atraen. Es una obra bastante celebrada de Brozic, que representa al 
conde de Thurn y á sus partidarios los descontentos de Bohemia, dentro del palacio de Hardschine el 23 de Mayo de 1618, al ser arrojados por la ventana. El cuadro es de algún efecto; hay en su conjunto animación y vida; más, si os fijáis en él, vuestra primera impresión se desvanece; los defectos abundan; su autor olvida con harta frecuencia las reglas más elementales del dibujo. Mentira parece que un artista que tan bien concibe ejecute tan mal. Es precisamente en el grupo más importante, en el grupo del centro, donde las mayores faltas se acumulan. Dos manos de dos distintos personajes, crispadas en la misma forma, constituyen además un verdadero defecto en que un artista no debe incurrir, la estética no admite estas coincidencias sino cuando deliberadamente se encaminan al desarrollo de la idea principal, no siendo este el caso del cuadro de Brozic. Hemos oído que alguien piensa proponer esta obra para una de las medallas de honor. Sería para el arte muy sensible que esa propuesta fuese aceptada por el jurado.

Los dos famosos Cristos de Munkacsy excitan extraordinario interés: son dos obras magníficas, sólidas, vigorosas; os dais cuenta en seguida de que aquellas figuras han sido trazadas por una mano magistral. iQue firmeza en el dibujo, que intensidad en el color, que armonía en la composición! Hay en estos dos cuadros algo de Rembrandt: el recuerdo de Rembrandt os asalta especialmente ante el "Cristo en el Calvario", que es en nuestra opinión el mejor de los dos lienzos de Munkacsy.

Del "Cristo ante Pilatos" es la tan ponderada figura de Cristo lo que menos nos seduce, no porque desconozcamos que la figura esté hecha de un modo admirable, sino porque está mal concebida. Munkacsy da a su Cristo ante Pilatos una fisonomía en extremo vulgar; es difícil acostumbrarse a la idea de que el fundador de una religión tan grande tuviese tan simple y banal aspecto como le da el artista. En cambio, cuando pinta a Cristo en la Cruz, Munkacsy nos lo presenta de un modo muy diferente, con una expresión acentuadísima, simbólica, y bajo formas casi her'cúleas.

Olvidemos la incoherencia; absorbamonos en la admiración de "Cristo en el Calvario", esa grandiosa obra de arte, gloria de la pintura contemporánea. No se ha hecho en nuestro tiempo, ni acaso en nuestro siglo, otro cuadro donde con mayor vigor se revele la inspiración del hombre. Munkacsy deja atrás a Delacroix; no llega a Rembrandt, pero lo sigue Contiene este cuadro portentoso una figura inimitable, la de la Magdalena. Su cabeza es hermosísima... icomo se vé en ella el dolor sublime y desesperado! iQue incomparable belleza hay en su actitud, en su expresión, en el juego de sus manos al cubrir con ellas el rostro y en sus flotantes cabellos rubios!

Expone también Munkacsy un fragmento de pintura decorativa, un proyecto de techo para el Museo de la Historia de las Artes de Viena. Es un género en que el gran pintor está ménos afortunado: la composición diríase que ha sido hecha de prisa, parece que está sin cóncluir; el estudio de la perspectiva resulta deficiente. Hay por ejemplo, en primer término una balaustrada cuyo plano vertical no corre paralelo al de la piedra angular en que termina; Munkacsy quiere pintarnos la ondulación del interior de la cúpula y buscando a todo trance el efecto apetecido, disloca la balaustrada que a la cúpula sirve de base, le hace seguir con todo el resto de la composición la curva ascendente y falsea la perspectiva, debilitándola, por tanto, en vez de vigorizarla. 
En este género de pintura es Hynais quien más se distingue entre los compatriotas de Munkacsy. Hynais trata los más diversos asuntos, ya mitológicos, ya alegóricos, ya puramente fantásticos; sobre todo uno de sus frisos contiene deliciosos primores; un proyecto de telón para el teatro Nacional de Praga nos gusta menos.

Payer nos presenta un náufrago en el hielo; el paisaje está bañado por esa luz polar que os impide saber si es de noche ó de dia; el astro que brilla á lo lejos puede ser lo mismo el sol que la luna: hay soberbias figuras de hombres helados en cuyo rostro se nota esa rígida contracción que les prestó una risa á la vez muda y sarcástica. Payer es un pintor excelente de la nueva escuela y su nombre merece ser retenido.

Los cuadros más notables de la sección alemana son los de Kuchl y los de Liebermann; Menzel expone sólo una extraña fantasia, un caprichoso juego de colores que no da idea de las grandes facultades que distingue á su autor.

Entre los cuadros de Liebermann y los de Kuchl, existe con frecuencia un parecido tan grande que á lo mejor cree uno que están pintados por la misma mano. La especialidad de ambos consiste en efectos de luz á través de grandes ventanas: Kuchl nos pinta unos jugadores de cartas realmente admirables y unas costureritas deliciosas, cuyos dedos diríase que se mueven. Una vieja y un zapatero, trabajando al lado de una ventana, son dos cuadros de Liebermann notabilísimos. De Liebermann es también una composición de distinta índole, muy interesante y muy bella. "Los inválidos"; se les vé á estos reunidos en su jardin en reposada actitud, mientras el sol penetra dulcemente á través de las espesas ramas que les dan sombra.

Ernesto García Ladevesse.

México, Siglo Diez y Nueve 9 de agosto de 1889. p. 2.

\section{DOCUMENTO No. 7}

\section{LA EXPOSICIÓN \\ UNIVERSAL DE PARÍS}

La pintura y la escultura italiana. Entre la Italia de Miguel Angel, de Vinci, de Tiziano y de Rafael, y la İtalia artística de nuestro tiempo, hay muchà distancia. Una transformación completa opérase en el arte pictórico italiano, transformación que aún no ha llegado á su desarrollo y que crea por el momento una verdadera crisis. Junto á Bimoni y Corelli, que se esfuerzan por conservar el sello de la tradicional escuela clásica, vemos á Boldini y á Carcano, donde el gusto moderno se revela en toda su expansion. Preciso es confesar que en Italia la vieja escuela se bate en retirada y que la jóven generacion lánzase afanosa en busca de nuevos horizontes. iLástima que, con frecuencia, en lugar de entregarse á su propio ideal la nueva generacion artística italiana, se limite 
á seguir las huellas de ciertas, escuelas muy á la moda! La de Rousseau, por ejemplo, tiene en Italia no pocos imitadores; pero aunque es una escuela sana y fecunda, siéntese algo así, como una vaga decepcion, al ver que los descendientes de aquellos que en el mundo del arte crearon tantas maravillas, se hallen tan léjos de sus predecesores en originalidad y en audacia.

Boldini es uno de los raros pintores italianos de nuestro tiempo que tienen fisonomía propia; hay en sus obras una nota personalísima que les da extraordinario relieve. Reúnense en Boldini un cúmulo de condiciones excepcionales. Pinta con expontaneidad, con gracia y con ligereza; sus figuras son vaporosas y aparecen todas animadas de un sentimiento que se escapa de sus ojos, de sus labios, de su expresion, ó que se refleja hasta en el menor detalle de sus actitudes. Podría llamarse á Boldini el pintor de las vibraciones la de la alegoría, la del amor al sacudir con intensidad el alma, la del remordimiento; hallan en ese artista consumado un intérprete fidelísimo y prodigioso. Esas tres vibraciones ha trasladado al lienzo con sorprendente habilidad en una especie de trilogía en que se combinan tres figuras de mujer, pues para Boldini la mujer es el elemento vibrante por excelencia. Las tres figuras son tres retratos, y al mismo tiempo, tres escenas, expresadas con un encanto seductor y con una sencillez magistral.

La deliciosa jóven que, á solas y llena de ilusion, se entrega á la más desbordada alegría, encuentran, sin embargo, severos criticos para los cuales tiene el defecto de aproximarse á la caricatura. Quieren esos críticos que aquella alegría sea más mesurada y olvidan acaso que la fuerza de esas expansiones suele ser cuestion de edad y de temperamento. Más unánime es el éxito de la airosa figura que al abotonarse el guante lleva á otra parte el pensamiento y la mirada, dejando asomar á la superficie el fuego que su corazon agita.

Carcano expone, junto á los cuadros de Boldini una campiña donde la influencia de Teodoro Rousseau se deja sentir poderosamente; Carcano, como Rousseau, cultiva, más que el arte, la "ciencia del paisaje"; en su campiña todo vive, todo contribuye, digámoslo así, al movimiento general; no hay, en realidad, primeros ni segundos términos; todo marcha á la vez, sin concentrarse sobre un punto determinado del panorama. Es la escuela moderna de las grandes perspectivas tal como lo practicó el autor de "El paseo de los castaños" y de la "Bajada de los Alpes."

Más personal resulta Carcano en su paisaje de género muy distinto, en que el resplandor del crepúsculo, que parece abrazar el cielo tras de unas montañas, refléjase sobre el agua en llamaradas ardientes, miéntras un pueblo se disipa en la sombra entre la luz y el reflejo. Es un hermoso sole morente de efecto intensísimo. No es tan grande el que produce un rincon del paisaje en que Carcano nos pinta unos juncos pues si en él hay toques felices, en cambio interesa poco.

Simoni y Corelli nos presenta dos cuadros de grandes dimensiones.

E1 del primero "Thais en el banquete de Alejandro," es una composicion complida y atrevida, que revela un trabajo enorme y facultades poco comunes.

Reinan en el palacio la confusion y el desorden propios de una bacanal; se ven algunas figuras cuyas contorsiones nos traen á la memoria á aquellos admirables artistas italianos de fines del siglo XV y del siglo XVI, de los cuales Miguel Angel fué la personificacion más inspirada. Pero, en su conjunto, la 
obra vastísima de Simoni aparece un tanto artificiosa á causa de la extraordinaria aglomeracion de figuras y de accidentes.

El "Ave María", de Corelli, de gusto más moderno, viene precedido de gran fama; la fotografía y el grabado nos lo habían hecho conocer; hay que confesar que es uno de los cuadros más interesantes que la Italia moderna ha producido. Por sus amplias dimensiones y por la disposicion escultural de algunas de sus figuras, puede decirse que esta obra pertenece al género de la pintura decorativa. Existe una vieja leyenda, segun la cual, San Pedro, al llegar de Galilea, abrió el primer surco en la campiña romana y sembró en ella el primer grano de trigo; por eso los segadores cuando el toque de la oracion suena, suspenden todos el trabajo y murmuran su plegaria mirando hácia Roma, donde San Pedro tiene su tumba. Tal es el asunto del cuadro de Corelli, hecho con más talento que inspiracion. Algunos de sus personajes no revelan hallarse poseídos del sentimiento religioso que el autor les ha querido prestar. La primera impresion que el "Ave María" de Corelli os causa, es excelente, más el cuadro pierde á medida que lo miráis Resiéntese la obra de cierta frialdad que neutraliza mucho el primer efecto de su pintoresca y hábil composicion.

Siguen á Boldini, á Carcano, á Simoni y á Corelli una pléyade de paisajistas; el paisaje parece ser el género de pintura que hoy más se cultiva al otro lado de los Alpes Citaremos un magnífico estudio de luz en medio de un bosque, de Emilio Borfa, obra de escasas dimensiones, de una trasparencia exquisita y de una ejecucion primorosa; Tommassi inclínase al paisaje impresionista, más no alcanza á impresionarnos; hay unos hermosos corderos de Segantini, que en sus paisajes á la inglesa se recrea en pintarnos esas verdes praderas que los franceses llaman verde enfermizo. Los paisajes de Bezzi y de Ciardi resultan poco acabados; Sartori lleva en los suyos el impresionismo hasta una exageracion del peor gusto posible.

Unos caballos de Gioli completan la seccion de pintura italiana; Gioli es un pintor de animales observador y concienzudo; busca las dificultades, las afronta y sale de ellas victorioso. Sus caballos son de un realismo exacto y, digámoslo así, penetrante.

En las salas que comprende esta seccion se ven dispersas varias obras de escultura, entre las que se destacan por su belleza, "La infancia de Benvenuto Cellini," de Caroni, y una graciosisima figura carnavalesca de mujer, de Luigi Ambrogi poseen ambas un encanto indecible y están ejecutadas con una delicadeza y una finura que rayan casi en el prodigio Caroni y Luigi Ambrogi han sabido dar al níveo mármol de Carrara la más sincera expresion de vida. Haced girar á la figura carnavalesca sobre su pedestal; su dorso es un primor; las labores del mármol parecen de encaje.

Despues viene Cecioni con un delicado grupo en que se ve á un pequeño galgo queriendo quitar á un niño un bizcocho. $\mathrm{E}$ niño levanta la mano para sustraer del alcance del perro la presa codiciada; más, al ver que éste insiste y se dispone á saltar, desespérase y grita.

No ménos bello es otro grupo, de Possina Carlo, en que una jóven se divierte en enseñar á un niño un racimo de uvas; el niño esfuérzase inútilmente por cogerlo; pero su expresion es la de la alegría; parece que está seguro de que aquellas uvas van á ser para él. 
Estas cuatro obras, por sí solas, bastarían para que brillase dignamente en la Exposicion Universal la escultura italiana de nuestro tiempo.

Ernesto García Ladevesse.

México. El Siglo Diez y Nueve. 13 de agosto de 1889 . p. 2

\section{DOCUMENTO No. 8}

\section{LA EXPOSICIÓN DE PARÍS LA PINTURA INGLESA}

Sabido es que los ingleses son malos coloristas. Quizás no es culpa suya. Si visteis alguna vez ponerse el sol tras los árboles de un square de Lóndres, habréis observado, de seguro, efectos de luz de una originalidad extraña. Suele ser aquella una luz finísima, pero un tanto vaga y difusa. Allí no adquieren los objetos el relieve que les da nuestra luz intensa y penetrante.

$\mathrm{Y}$, sin embargo, bajo la influencia de esa ley de los contrastes que tan a menudo rige las manifestaciones de la vida, es precisamente en la acción de pintura inglesa donde hay que ir' a admirar la más perfecta maravilla de relieve y de colorido que contienen las secciones extranjeras del Palacio de Bellas Artes. El cuadrito de Alma Tadema Expectation, es un verdadero prodigio de finura, de pureza y de armonía; es una joya artística de inapreciable valor. Su ejecución es tan exquisita como su idea es poética. Alma Tadema nos ofrece en Expectation una página deliciosa donde se recrean á la vez nuestros ojos y nuestro espíritu.

Ciertamente, no hallamos en la obra tan celebrada del famoso pintor inglés una novedad absoluta, ni los principales elementos que constituyen lo que en el arte se llama una creación. El éxtasis que sentís contemplando esta obra bellisima es interrumpido por una reminiscencia que renueva ante vosotros la huella luminosa de aquellos delicados miniaturistas del Renacimiento. Mas el efecto fascinador de Expectation es un hecho innegable; la obra de Alma Tadema os encanta, os seduce, derrama en vosotros no sé que mágico filtro que, al hechizaros, os esclaviza, llenándoos de inefable dulzura.

La escena es simple y elocuente: sobre un banco de mármol que avanza junto al mar en forma de rotonda, destácase sentada una figura de mujer. Coloca ésta delante de sus ojos, en graciosa actitud, uno de sus brazos para ayudarse á concentrar la mirada sobre una embarcacion que viene á toda vela de un puerto vecino. Apóyase el banco de mármol en un muro tambien de mármol, detrás del cual se eleva el árbol del amor, con sus ramas floridas. Algunas de sus hojas cayeron dentro del muro.

Un vapor pasa á lo lejos por el horizonte; á la izquierda, á alguna distancia, mueve el viento la superficie del mar, levantando de ella copos de espuma.. Cuando la embarcacion que viene del puerto llegue al pié del muro, la luz del 
sol se habrá apagado, aquel vapor se habrá ido, la nívea espuma creada por el beso del mar y del viento se desvanecerá entre la sombra; la ciudad que enfrente se distingue quedará dormida, y alguien pasará sobre aquel muro como las hojas del árbol florido pasaron.

Ménos felices hallamos á Alma Tadema en un cuadro más complicado, The women of Amphissa, que tambien llama poderosamente la atencion de la crítica y del público; la escena está inspirada en un pasaje de la obra de George Eliot, Daniel Deronda, pasaje que recuerda á su vez una relacion de Plutarco; varias jóvenes bacantes griegas, unas con la cabeza coronada de yedra, otras teniendo todavía en sus manos los instrumentos con que acompañaron sus danzas, se despiertan echadas sobre la plaza del mercado, en cuyas duras losas durmieron. Las actitudes están muy bien estudiadas: una estira los brazos para quitarse la pereza; otra se incorpora fatigada; alguna duerme todavía; otra abre indiferente sus ojos; otra, sentada en el suelo, tiene la cabeza soñolienta entre sus manos; otra coge fruta que le ofrecen las matronas, quienes, para no despertarlas, fueron llegando en silencio. Las clásicas bohemias tienen casi todas sus rostros amarillos, envejecidos por la errante luz de las antorchas.

The women of Amphissa es un cuadro interesante La composicion de sus principales figuras es rica en actitudes. A primera vista se nota la mano de un maestro consumado. Mas el color que en la obra domina no es del mejor gusto: Alma Tadema incurre en esta obra en el defecto habitual á muchos pintores ingleses, que es el abuso de los colores cenicientos ó lechosos.

Leighton es tambien de los que flaquean por el colorido. Su cuadro Camptive Andromache seria una obra de un vigor excepcional y de un efecto poderoso si la combinacion de sus colores fuese más afortunada. Aparte de la excelente figura de la mujer de Héctor, noble personificacion del amor conyugal, hay en el cuadro de Leighton un grupo magnífico, compuesto de cuatro gallardas y airosas jóvenes. Todas ellas cogen agua, no pueden ser más graciosas, más diversas, y al mismo tiempo más originales sus actitudes. Tiene este cuadro un corte clásico, en el buen sentido de la expresion; sus figuras son figuras esculturales, pero sin la menor dureza; la gracia es su principal atractivo.

Leader es entre los pintores ingleses el que representa el paisaje moderno, en el ha hallado un poderoso intérprete la nueva fórmula introducida en este género de pintura por los paisajistas franceses de 1848. Nos presenta Leader un admirable paisaje crepuscular de efecto intensísimo, obra de primer órden, magistral, en la que la armonia del conjunto se une á la primorosa perfeccion de los detalles.

Todo en él está estudiado á conciencia y ejecutado con mano experta y segura. Es una composicion inspirada, sólida, acabadisima, quizás demasiado densa a causa, sin duda, del exceso de detalles que su autor ha ido en ella acumulando.

En un paisaje de Murray, Britania's Anchor hallamos unos efectos bruscos de colorido que no carecen de novedad y de atrevimiento; hay en él toques vigorosos. Puede incluirse á Murray en la novísima escuela de los impresionistas.

Millais, Herkomer y Fildes, cultivan el retrato con gran fortuna. Los de Millais, se distinguen por su naturalidad; es Millais en este género el pintor á la moda al otro lado del Canal de la Mancha, y no nos parece su triunfo 
inmerecido. Entre los seis retratos que expone en el Palacio de Bellas Artes, los mejores son el de W. E. Gladstone y el de un pintor; obras desposeídas, digámoslo así, de artificio, hechas segun se vé, sin esfuerzo alguno, obedeciendo á la más sincera impresion del artista. Es el carácter distintivo de los retratos de Millais.

Herkomer es más vigoroso: el retrato de Miss Catherine Grant lleva en sí una nota personalísima; hay en su factura una sólidez extraordinaria y una expresion de vida que se impone.

La acuarela ocupa grande espacio en la seccion de pintura inglesa. Los ingleses son acuarelistas muy notables y así lo acreditan actualmente en París en la Exposicion de la rue de Seze Alma Tadema nos presenta dos obras de este género, diríase que una de ellas le ha servido de estudio para su célebre cuadro Expectation. Lewis Walker, Willie y Langley son con Alma Tadema los más inspirados acuarclistas que hoy Inglaterra posee.*

Ernesto García Ladevesse.

México El Siglo Diez y Nueve., 21 de agosto de 1889. p. 1.

* La transcripción periodística ha sido respetada literalmente. 